\title{
GEOGRAFÍA, POLÍTICA Y ECONOMÍA DEL REPARTO LIBERAL EN LA MESETA PURÉPECHA, 1851-1914
}

\author{
Fernando Pérez Montesinos \\ University of California, Los Angeles
}

\section{INTRODUCCIÓN}

in causar mucho ruido, de modo más bien discreto y $\checkmark$ gradual, la imagen que teníamos del proceso desamortizador de la segunda mitad del siglo xIx y principios del xx (y sus consecuencias) ha experimentado un cambio profundo en las últimas tres décadas y media. ${ }^{1}$ Ya nadie, por ejemplo, podría sostener de manera persuasiva que en vísperas de la revolución mexicana, en un estado como Michoacán - poblado por un conjunto variopinto de pequeñas propiedades, rancherías, ranchos, haciendas y arriba de 250

Fecha de recepción: 27 de junio de 2016

Fecha de aceptación: 14 de julio de 2016

1 Para balances historiográficos véase Menegus, "La venta de parcelas", pp. 71-78; SCHEnK, "Muchas palabras", pp. 215-227; Marino, "La desamortización de las tierras", pp. 33-43; Kourí, "Interpreting the Expropriation”, pp. 69-117; Escobar y ButLer, “Introduction”, pp. 33-76. 
comunidades indígenas-, poco más de $97 \%$ de la población rural carecía de propiedades agrícolas como resultado, entre otras cosas, de la aplicación de la conocida Ley Lerdo de 1856. ${ }^{2}$ Las razones detrás de este cambio son muchas y están aún por examinarse, aunque no hay duda de que la bibliografía relevante no sólo es hoy más numerosa que nunca, ${ }^{3}$ sino que guarda características propias que la distinguen de manera cada vez más marcada de la historiografía clásica asociada con autores como Andrés Molina Enríquez, Wistano Luis Orozco, George M. McBride o Frank Tannenbaum.

La "nueva" historiografía ha abandonado la visión centralizada, generalizante y hasta cierto punto unívoca que solía caracterizar a su antecesora. A diferencia de muchas de las interpretaciones precursoras, el enfoque que ahora domina entre los especialistas es patentemente local y descentralizado. El pormenorizado trabajo llevado a cabo en archivos municipales, estatales y algunos federales - muchos de los cuales habían sido previamente poco usados o de plano largamente ignorados - ayuda a explicar tal mudanza de perspectiva. ${ }^{4}$ La riqueza documental de estos

${ }^{2}$ Así lo afirmaba el trabajo pionero (y, pese a sus desaciertos, todavía informativo y perspicaz) de McBRIDE, The Land Systems, pp. 140-142 y 153156. Véanse las también precursoras críticas al trabajo de McBride y otros autores pioneros como Frank Tannenbaum hechas por Guerra, México: del Antiguo Régimen, pp. 473-496 y Meyer, “Haciendas”, pp. 477-509.

${ }^{3}$ Mis propias pesquisas arrojan una cifra de alrededor de 150 publicaciones (entre libros, capítulos de libros y artículos de revistas académicas) salidos entre 1980 y 2015. Agradezco a Tatiana Pérez Ramírez haber compartido tanto los resultados de su búsqueda como su texto (aún inédito) "Tendencias en la historiografía sobre la desamortización de las tierras de los pueblos indígenas en México de 1856 a 1910”.

${ }^{4}$ Cuestión señalada en su momento por MARINo, "La desamortización de las tierras". 
acervos y el carácter detallado de sus fuentes han permitido una reconstrucción mucho más puntual de numerosas localidades situadas en estados actuales como México, Oaxaca, Hidalgo, Veracruz, Jalisco y Michoacán (entre otros). ${ }^{5}$ No es de sorprender, entonces, que los pilares documentales en los que la historiografía clásica descansaba - la Ley Lerdo de 1856, las leyes de colonización y terrenos baldíos de 1883 y 1894 y los censos de 1895, 1900 y 1910 - hayan perdido buena parte de su alguna vez irrefutable poder explicativo. La imagen dicotómica ofrecida por los censos porfirianos - hacendados, por un lado, y peones jornaleros, por el otro - y la fuerza inexorable atribuida a la Ley Lerdo han sido paulatinamente sustituidas por un cuadro significativamente más heterogéneo y hasta enrevesado del campo mexicano en el siglo XIx y las primeras décadas del xx.

${ }_{5}$ Para el Estado de México puede consultarse el aún fundamental estudio de Menegus, "Ocoyoacac", pp. 33-78 y, más recientemente, los estudios de Marino, "La modernidad a juicio", pp. 237-264; СAMACHO Pichardo, "Desamortización y reforma agraria”, pp. 287-310; y BirriChaga y Salinas Sandoval, "Conflicto y aceptación”, pp. 207-252. Para Oaxaca, el volumen colectivo de SÁnchez Silva (coord.), La desamortización civil; Mendoza García, Municipios, cofradias; y Menegus, La Mixteca Baja. Para las huastecas hidalguense y veracruzana, el estudio básico de Escobar y SCHRYER, "Las sociedades agrarias", pp. 1-21; EsCOBar y Gordillo, “¿Defensa o despojo?”, pp. 17-74. Para Jalisco, los también básicos trabajos de KNOwLTON, "La individualización”, pp. 24-61 y MeYer, "La Ley Lerdo”, pp. 189-212; más recientemente, Gómez SANTAna y Gómez Santana, "Mujeres y propiedad social”, pp. 545-563. Para Michoacán, el todavía importante artículo de KnOwlton, "La división de las tierras", pp. 3-25, y los agudos estudios de Purnell, "With All Due Respect'”, pp. 85-121 y RoseberRy, “'El estricto apego a la Ley”, pp. 43-84; más recientemente, el texto de STAuffer, "Community”, pp. $149-180$. 
Este cambio de lente y escala, acompañado por supuestos teóricos más robustos, también ha permitido ofrecer un perfil mucho más sofisticado de la vida local e interna de las comunidades indígenas. En contraste con la visión canónica que dominó buena parte del siglo xx, cuando hoy los historiadores profesionales hablan de "comunidades indígenas" se entiende que lo hacen pensando en colectividades complejas, cuya identidad corporativa no sólo estaba lejos de inhibir el surgimiento de desigualdades materiales y rivalidades internas, sino que era de hecho el resultado de múltiples y constantes negociaciones y acomodos entre los miembros de cada localidad. ${ }^{6}$ Lo mismo puede decirse del régimen comunal de la tierra. En la actualidad, pocos profesionales de la historia argumentarían de manera convincente - como solía hacerse en el pasado - que se trataba de una forma de tenencia simple, esencialmente uniforme e invariable. Por el contrario, casi toda la bibliografía relevante de las últimas décadas insiste en señalar que la propiedad comunal en México años antes y después de la Revolución admitía de hecho un conjunto más bien variado de derechos que sancionaban y permitían al mismo tiempo distintos tipos de usufructo, tanto individuales como familiares y colectivos. ${ }^{7}$

${ }^{6}$ Véanse al respecto las agudas reflexiones de Buve, "Un paisaje lunar", pp. 121-151. Aunque a veces innecesariamente denso y embrollado, véase también el libro de Mallon, Peasant and Nation.

7 Para una síntesis véase Escobar, Las estructuras agrarias y Menegus, Los indios en la historia. Aunque basado en el análisis de Inglaterra, Francia y Cataluña, el trabajo de Congost, "Property Rights", pp. 73-106, es de gran utilidad para entender la complejidad histórica detrás de los derechos de propiedad sobre la tierra en su conjunto. 
Otro aspecto distintivo del giro interpretativo de las últimas décadas está relacionado con lo que podemos llamar, de manera un tanto tosca, la centralidad de la participación indígena. Hoy en día es cada vez más difícil sostener la perspectiva unilateral de muchos estudios clásicos, en la que terratenientes y autoridades liberales eran presentados virtualmente como los únicos actores relevantes del proceso desamortizador. La historia de este proceso es ahora examinada desde un punto de vista diametralmente distinto. Las comunidades y sus miembros ya no son tratados como personajes secundarios con poca capacidad de incidir en el curso de los acontecimientos, testigos más o menos inermes o rejegos (pero sólo testigos al fin) del desmantelamiento de sus tierras.

De hecho, el poder de intervención de los pueblos y grupos populares en general ha quedado ampliamente establecido, al grado de que hablar de "participación indígena" o "participación popular" de manera genérica resulta cada vez más insatisfactorio. El reto ahora consiste no sólo en señalar, sino en documentar y explicar el carácter heterogéneo y variable de dicha participación. De ahí, en parte, que el principal foco de atención (a veces, incluso, el único foco de atención) de muchos estudios sea la identificación y catalogación de las "estrategias" - ya sea de resistencia, acomodo o aquiescencia - empleadas por quienes hasta hace no tanto eran considerados incapaces de hacer frente a las políticas liberales salvo mediante ocasionales arrebatos de furia y actos violentos de desesperación. ${ }^{8}$

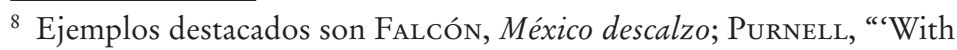
All Due Respect”; Escobar y Gordillo, “¿Defensa o despojo?”. Para 
En suma, estas y otras tantas contribuciones han resultado en un verdadero giro historiográfico cuyos beneficios no pueden sino ser reconocidos y hasta aplaudidos. Con todo, lo que aquí quisiera argumentar es que, pese a sus innegables virtudes, dicho giro también ha traído consigo algunos problemas importantes. Si bien ha ayudado a subsanar varias de las deficiencias más patentes de la tradición clásica - su falta de evidencias documentales locales, su perspectiva centralizada y unilateral del proceso desamortizador, su limitado entendimiento de la propiedad comunal y las comunidades -, al mismo tiempo ha dado pie a investigaciones cuyo carácter es con frecuencia marcadamente más descriptivo que explicativo. Esto es, se trata de investigaciones que suelen ser muy meticulosas a la hora de referir episodios (aparentemente) aislados del proceso desamortizador en tal o cual localidad o municipio, pero que con frecuencia no ofrecen ni una cronología precisa de los episodios que relatan ni mucho menos un análisis de cómo estaban, de hecho, relacionados con circunstancias y condiciones más amplias (regionales, estatales, nacionales).

Mi impresión, en otras palabras, es que (al menos en parte) hemos pasado de una historiografía que por lo general hacía muy poco caso de las particularidades regionales y locales, a otra cuyo énfasis casi exclusivo en lo local y (sobre todo) lo episódico la ha llevado con frecuencia a descuidar

una crítica al enfoque de las "estrategias" véase Boenм, "Las comunidades de indígenas", pp. 145-175. Véanse también las interesantes observaciones de Thomson, “¿Convivencia o conflicto?”, pp. 205-237. Un reciente y espléndido intento por desagregar lo popular aplicado a las insurgencias de principios del siglo xix puede verse en GRANADOs, En el espejo baitiano, pp. 31-55. 
el examen sistemático de las causas, el contexto y la evolución del proceso desamortizador. Si por un lado la tradición clásica basaba su explicación de dicho proceso en la especulación teórica y en un cuerpo documental limitado, por el otro, la "nueva" historiografía suele caer en un empirismo casuístico que le impide muchas veces elaborar una etiología, aunque sea aproximada, de los hechos que tan diligentemente ha ayudado a sacar a la luz. A diferencia del canon clásico que intentaba dar razones, si bien de manera equívoca y hasta simplista, acerca de lo que suponía había sido un ataque irresistible a la propiedad comunal, muchos estudios recientes parecen desentenderse de cualquier discusión acerca de las razones y factores que hicieron posible poner en marcha - así sea de manera parcial e inconsistente- las políticas liberales de la tierra. En suma, hace falta un examen más sólido de por qué, cuándo y según qué etapas ocurrió la transformación de la propiedad comunal.

No se trata de defender un regreso al canon clásico. Muchas de las premisas en las que descansaba han sido lo suficientemente refutadas como para intentar semejante empresa con éxito. Tampoco se trata de restarle importancia a los estudios locales. El problema, creo yo, es menos de escala (del tamaño del objeto de estudio) que de método y de miras. Lo que me interesa señalar es la necesidad de pensar formas de análisis que vayan más allá de la sola documentación y el solo registro (disperso) de hechos. De lo que se trata, en otras palabras, es de combinar la ambición explicativa de los trabajos clásicos (su interés por establecer conexiones entre acontecimientos, su espíritu analítico y su visión de conjunto) con el esmero por los hallazgos empíricos de la historiografía contemporánea. 
Lo que propongo, entonces, es examinar la historia del reparto liberal en la meseta purépecha a partir de un conjunto de elementos o factores clave que, espero, permita un entendimiento más general de las causas, la evolución y las consecuencias del proceso desamortizador y que, al mismo tiempo, haga justicia a las peculiaridades de esta región montañosa michoacana. Se trata de un intento por sistematizar y explicitar factores que, salvo en casos excepcionales, ${ }^{9}$ aparecen en la historiografía o bien de manera desarticulada o sólo mencionados de modo tangencial, sin que realmente formen parte del análisis de los casos estudiados. Todavía más, se trata de un esfuerzo por identificar, abstraer y luego sustanciar con evidencia concreta elementos que, sostengo, son comunes a la mayoría de las regiones y localidades en donde la desamortización y otros procesos similares tuvieron lugar. Decir que estos elementos son comunes, sin embargo, no significa que hayan actuado exactamente del mismo modo en todos los casos. Al contrario, se conjugaron de forma distinta según cada caso y, en consecuencia, dieron como resultado múltiples historias distintas una de la otra. Lo importante, entonces, es que el análisis de estos elementos y de las diferentes formas en que se combinaron lo mismo permite comparar casos locales por encima de sus especificidades que dar cuenta de manera precisa de sus singularidades.

Lo que busco al proponer la elaboración de un cuadro analítico como el que enseguida se desarrolla es, en última

${ }^{9}$ Kourí, A Pueblo Divided sigue siendo el trabajo más acabado que existe sobre el fin de la propiedad comunal a finales del siglo xIx y principios del xx. Véase también Menegus, La Mixteca Baja; Mendoza García, Municipios, cofradias; y Escoвar, "Estudio introductorio", pp. 19-98. 
instancia, defender la idea de que el reparto fue esencialmente un producto coyuntural. Entender el reparto liberal en estos términos nos obliga a no dar por hecho, como a menudo se hace, su surgimiento y desarrollo; nos obliga, en efecto, a examinar de manera puntual y ordenada los acontecimientos de los que derivó y a los que dio origen. Un producto esencialmente coyuntural, esto es, por definición, una combinación de condicionantes "estructurales" y cambios circunstanciales de última hora en que los actores involucrados fueron definiendo sus posturas y acciones sobre la marcha $-\mathrm{y}$ cuyos resultados fueron, por lo tanto, en buena medida inesperados.

\section{CINCO FACTORES CLAVE}

Veamos un conjunto de elementos o factores clave. En primer lugar, están aquellos que a falta de un mejor término hay que llamar estructurales. Se trata de elementos relativamente estables del paisaje geográfico e institucional que por sí solos no son causa de nada, pero que tampoco pueden concebirse como meros telones de fondo de la acción. Definen - a veces de manera intransigente, a veces de forma más o menos flexible y esporádica - los contornos del quehacer práctico. Lo mismo inhiben que hacen posibles determinados patrones de acción; en una palabra, lo suyo es hacer más probable la incidencia de determinados comportamientos y actividades en comparación con otros. Dos de estos elementos me parecen esenciales para analizar la historia del reparto liberal en la meseta purépecha. Por un lado, la topografía y el peculiar régimen hidrológico de la región que, de hecho, la dividía (y aún divide) en dos áreas claramente distinguibles y diferenciadas. Por el otro, el 
marco legal creado por los liberales para desmantelar la propiedad comunal: la Ley Lerdo de 1856, por supuesto, pero también la ley de reparto del estado de Michoacán, promulgada unos años antes, en 1851.

En segundo lugar, hay que considerar aquellos elementos que marcan cierto giro en la inercia de los sucesos. Podemos referirnos a ellos, de modo un tanto torpe y redundante, como factores coyunturales que a su vez ayudan a engendrar otras coyunturas más pequeñas y localizadas. Se trata de momentos que, incluso si lo hacen sólo de manera provisional, establecen un nuevo orden de cosas o, mejor dicho, que logran crear un ambiente de urgencia propicio para promover un nuevo orden de cosas. El fin de la ocupación francesa en 1867 representa tal momento en la historia del reparto liberal en Michoacán - y también en la historia de la desamortización en otras muchas regiones de México.

Hace falta, con todo, un tercer elemento, un factor precipitante que obligue de hecho a hacer valer en la práctica el sentimiento de urgencia recién creado y lleve a desencadenar una serie de respuestas por parte de quienes hasta ese momento habían permanecido más o menos indiferentes. En la meseta purépecha, ese factor lo constituyó primero, a partir de 1868, la aplicación de un nuevo impuesto sobre la tierra que si bien afectaba también a las propiedades rurales y urbanas particulares, era en especial gravoso para la propiedad comunal y las comunidades. En un segundo momento, que comenzó en la segunda mitad de la década de 1880, el revulsivo vino con el tendido de la red ferroviaria, cuya construcción dio origen a una demanda sin precedentes de madera y creó incentivos extraordinarios para abrir los bosques comunales de la región a la explotación comercial industrial. 
Un cuarto factor a considerar es la capacidad de acción de todos los actores involucrados en una coyuntura dada. Por "capacidad de acción" me refiero no sólo a la facultad de resistir o lidiar con circunstancias adversas, sino a la habilidad de propios y extraños de reorientar esas circunstancias, según iban cambiando, para hacerlas servir a sus múltiples intereses. Es este juego de intereses, íntimamente ligado tanto a la geografía física como a la particular configuración social de la región, lo que le dio al reparto liberal en la meseta su peculiar trayectoria y resultado.

Finalmente, el quinto factor que me gustaría aquí destacar tiene que ver con lo que denominaré elementos agravantes. Es decir, sucesos o fuerzas que, o bien magnifican los alcances de una coyuntura determinada mientras ésta tiene lugar, o bien extienden sus secuelas una vez que ha pasado su momento más álgido. Esto fue, creo yo, lo que sucedió con el sutil, pero a fin de cuentas inexorable crecimiento poblacional de la meseta purépecha: pasado ya el ímpetu de las autoridades liberales por el reparto (c. 1875), las presiones demográficas, combinadas con el fin de la prohibición legal a la compra venta de tierras comunales, dieron pie a una nueva ronda de fraccionamientos de tierras comunales cuyo efecto acumulado a largo plazo fue quizá igual de importante que la misma política de reparto.

Lo que sigue es una síntesis apretada de cómo todos estos factores, estructurales, coyunturales, precipitantes, operativos y agravantes, se combinaron para poner en marcha lo que creo fue el primer desafío significativo en el siglo XIX al régimen comunal de la tierra en una de las regiones indígenas más importantes de Michoacán y, por extensión, de México. 


\section{UNA FORMA DE TENENCIA COMUNAL, TRES TIPOS DE TIERRA, DOS MESETAS}

A mediados del siglo xIx, cuando fueron promulgadas la Ley Lerdo y la ley michoacana de reparto, las comunidades indígenas de la meseta purépecha probablemente estaban en posesión de poco más de la mitad de todas las tierras de la región: unas 230000 ha de un total aproximado de 447000 . Cifra notable, sobre todo si se hace notar que las haciendas locales posiblemente sólo ocupaban un cuarto (quizá mucho menos) del territorio disponible. El otro cuarto (quizá mucho más) estaba en manos de numerosos pequeños y medianos propietarios particulares. ${ }^{10}$ La propiedad comunal de la tierra en la meseta se encontraba, a grandes rasgos, dividida en tres principales partes. Cada una de esas partes, sostengo, respondía en buena medida a la peculiar configuración topográfica de la región: una mayor altitud sobre el nivel del mar respecto a regiones vecinas; la presencia de numerosos cerros y montañas boscosas; y la existencia de terrenos relativamente planos y aptos para el cultivo situados entre elevaciones montañosas. ${ }^{11}$

${ }^{10}$ Es sumamente difícil ofrecer cifras precisas con base en los registros documentales existentes y fuentes secundarias relevantes. Estas cantidades deben tomarse con cautela y sólo verse como un cálculo informado, pero en última instancia incierto, producto del cotejo de diversas fuentes elaboradas con posterioridad a la segunda mitad del siglo xIx. Véanse los indispensables trabajos de Acosta Espino y Embriz Osorio, "Territorios indios", pp. 119-195, y Embriz Osorio, "Propiedad, propietarios, pueblos indios", pp. 233-271. Igualmente útil es GARIBAY OrOzco y Bocco Verdinelli, Cambios de uso del suelo. Algunos datos valiosos fueron extraídos de AGN, FOP, Agricultura, "Inventario relativo a Estadística Agrícola. Michoacán, 1910”, leg. 2, c. 8, exp. v1.

${ }_{11}$ Para descripciones de la época véase Pérez Hernández, Compendio de la geografía, pp. 28-35; Velasco, Geografía y estadística, pp. 163-176. 


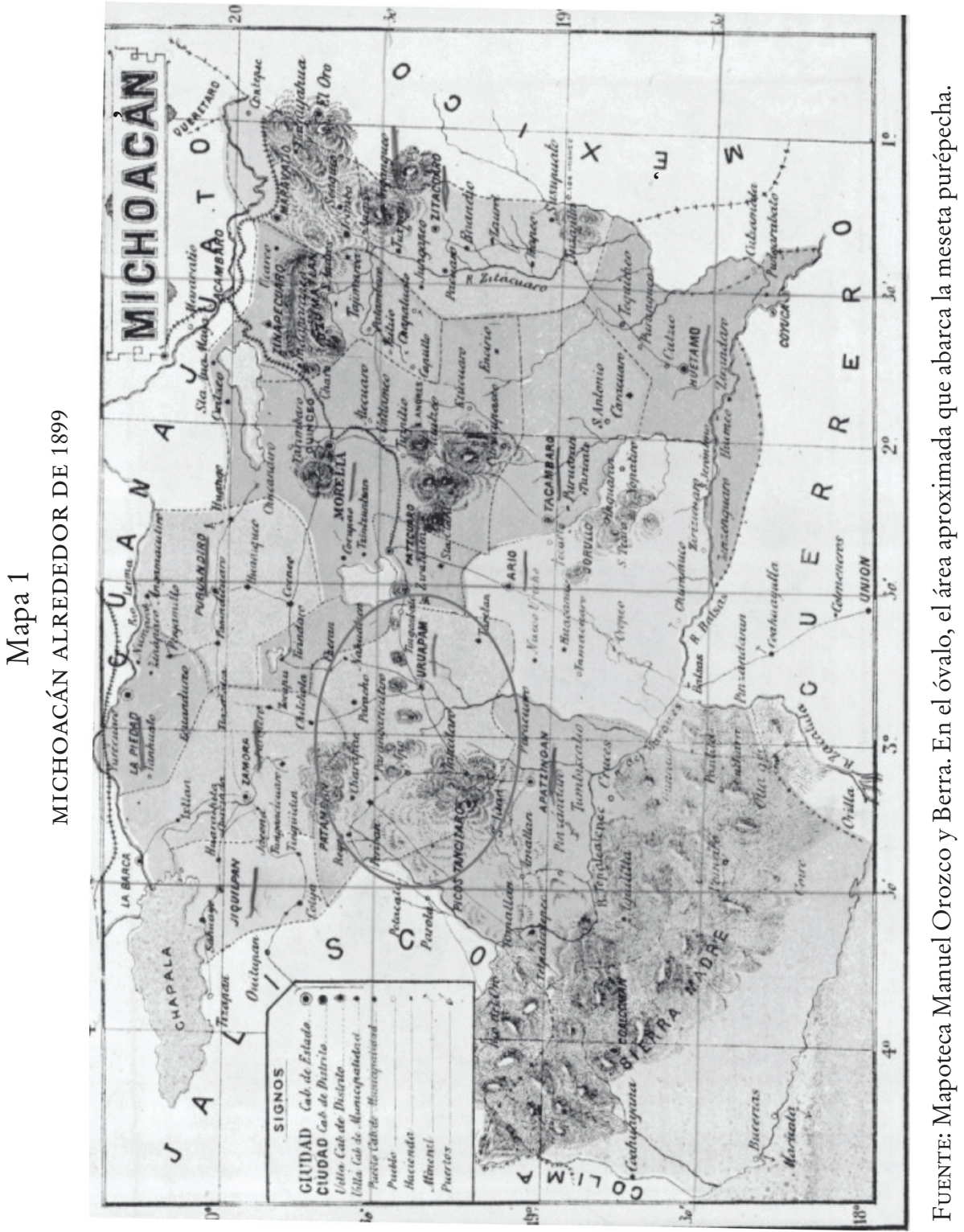


Por regla general, los asentamientos de la meseta estaban estratégicamente situados a un lado de las faldas de los cerros en los terrenos planos. Esta ubicación ofrecía varias ventajas. Durante la colonia permitió que la construcción y expansión de cascos urbanos - la primera de las tres partes en las que se dividía la propiedad comunal - se diera con relativa naturalidad. ${ }^{12}$ Ahí, en los cascos urbanos, se encontraban los lotes, propiedades familiares que eran a la vez espacios habitacionales y de trabajo. Los lotes tenían tres secciones bien definidas: los trojes, las cocinas y los solares. Los trojes formaban la edificación principal y servían tanto de graneros como de dormitorios. Las cocinas también podían ser usadas como dormitorios, aunque su propósito principal, naturalmente, era la preparación de alimentos. Los solares se usaban tanto para el almacenamiento de madera como para el mantenimiento de huertas en las que se sembraba una variedad importante de vegetales y frutas e incluso un poco de maíz. ${ }^{13}$

Otra ventaja de que los asentamientos en la meseta purépecha estuvieran situados en planicies era que facilitaban actividades esenciales como el cultivo y el pastoreo. De ahí, quizá, el término local de "planes", usado a veces para referirse a los terrenos agrícolas que en otros lados se conocían como tierras de común repartimiento - el segundo componente principal de la propiedad comunal. Por lo regular, los planes rodeaban el casco urbano, pero algunos también podían ubicarse a cierta distancia, detrás de cerros y

12 Garibay Orozco y Bocco Verdinelli, Cambios de uso del suelo, pp. 21-28 y West, Geografía cultural, pp. 69-86.

13 Véanse Azevedo Salomao (ed.), La vivienda purépecha y García MorA, El troje purépecha. 
montañas. De modo crucial, aunque estas tierras agrícolas pertenecían colectivamente a las comunidades, su usufructo era de hecho asignado de manera individual y familiar. ${ }^{14}$

La ubicación estratégica de los asentamientos ofrecía una última gran ventaja: el acceso a tierras adicionales para la agricultura y a los abundantes cerros boscosos de la región - la tercera y última parte en la que se dividía la propiedad comunal. A diferencia de los lotes urbanos y los planes divididos en parcelas familiares, estas tierras adicionales por lo regular permanecían sin ser asignadas a algún miembro de la comunidad en particular y su usufructo se destinaba, al menos en principio, para el beneficio entero de la comunidad. Algunas comunidades las aprovechaban para pastar su propio ganado, pero también se rentaban a terceros, ya sea para ganado o para cultivo. En contraste, el uso y acceso a los bosques estaban exclusivamente reservados para los miembros de la comunidad. Aunque la extracción de madera (para combustible doméstico, construcción y elaboración de artesanías) se daba en grupos o de manera individual, la parcelación de los montes estaba estrictamente prohibida. Los bosques, en otras palabras, eran terrenos comunales. ${ }^{15}$ La geografía física incidía de otra manera también fundamental en el arreglo socioeconómico de la meseta purépecha. Si por un lado su topografía prescribía una misma configuración de la propiedad comunal para todas las comunidades de la región, su régimen hidrográfico establecía una

14 Véase Garibay Orozco y Bocco Verdinelli, Cambios de uso del suelo y García Ávila, Las comunidades indígenas, pp. 49-62.

15 García Ávila, Las comunidades indígenas; West, Geografía cultural, pp. 85-87; Beals, Cherán, pp. 20-21, 59 y 92; Espín DíAz, Tierra fría; "Catastro de los bosques", pp. 95-110. 
clara línea divisoria entre ellas. Durante la temporada de lluvias (de finales de junio a noviembre), la precipitación solía ser constante y nutrida. Las abundantes lluvias contribuían a abastecer las corrientes y acumulaciones de agua de la región. Sin embargo, las características físicas de la meseta impedían una distribución uniforme del agua. Al interceptar buena parte de la lluvia y utilizarla para regenerar su propio follaje, los bosques limitaban la formación de cuerpos de agua de gran tamaño en las tierras de mayor altitud. Por su parte, debido a su alta porosidad y drenaje, los suelos locales también impedían la concentración de agua de lluvia en las partes más elevadas. De este modo, el agua que no era retenida por el bosque se filtraba al subsuelo y, dada la elevación y lo escarpado del terreno no agrícola, viajaba hasta llegar a tierras más bajas en donde alimentaba los ríos que ahí se formaban. Sólo las partes relativamente bajas de la meseta podían, entonces, contar con cuerpos y corrientes de agua de importancia. Las zonas altas de la serranía, en contraste, únicamente tenían acceso a una serie de manantiales menores que poco a poco iban disminuyendo su nivel a lo largo del año. En el punto más alto de la temporada de secas, aproximadamente de marzo a mayo, muchos de estos manantiales llegaban incluso a agotarse. ${ }^{16}$

Este desequilibrio en la distribución del agua dio como resultado la formación de dos zonas patentemente diferentes dentro de la meseta. Por un lado, estaba lo que llamaré la meseta alta, en donde la falta de agua obligaba a practicar

\footnotetext{
16 Calder, Hofer, Vermont y Warren, “Towards a New Understanding”, pp. 3-10; Ávila García, Escasez de agua, pp. 47-88 y 136-138; “Noticias hidrográficas", 1886, pp. 39-43, 58-59 y 87-90.
} 
la agricultura de temporal y cuya economía se encontraba en buena medida dirigida al autoconsumo, los mercados locales y el intercambio dentro de la región. El cultivo más importante, aunque no exclusivo, era el maíz. También se sembraban y comerciaban trigo y distintos tipos de frutas y vegetales. El trabajo con la madera era esencial, al grado que en algunas poblaciones podía ser tanto o más importante que las actividades agrícolas. ${ }^{17}$

\section{Cuadro 1}

LAS DOS MESETAS

\begin{tabular}{llll}
\hline & Meseta baja & \multicolumn{2}{c}{ Meseta alta } \\
Comunidad & Municipio c. 1869 & Comunidad & Municipio c. 1869 \\
\hline San Gabriel** & Los Reyes & Cherán & Cherán \\
Parangaricutiro & Parangaricutiro & Cherán-Atzicurin & Cherán \\
Paricutín & Parangaricutiro & Arantepacua & Nahuatzen \\
Zirosto & Parangaricutiro & Comachuen & Nahuatzen \\
San Francisco Peribán** & Peribán & Nahuatzen* & Nahuatzen \\
Peribán* & Peribán & Sevina & Nahuatzen \\
Apo* & Tancítaro & Turícuaro & Nahuatzen \\
Tancítaro* & Tancítaro & Ahuiran & Paracho \\
Ziracuaretiro* & Taretan & Aranza & Paracho \\
Taretan** & Taretan & Charapan & Paracho \\
Tingambato & Taretan & Cocucho & Paracho \\
San Ángel Surumucapio** & Taretan & Corupo & Paracho \\
Angahuan & Uruapan & Nurio & Paracho
\end{tabular}

17 Véanse fuentes en el cuadro 1. También, "Catálogo de las frutas", pp. 17-18, 38 y 42; y "Noticia no. 3 sobre ganadería”. 


\begin{tabular}{llll}
\hline & Mesetabaja & \multicolumn{2}{c}{ Meseta alta } \\
Comunidad & Municipio c. 1869 & Comunidad & Municipio c. 1869 \\
\hline Capacuaro & Uruapan & Paracho & Paracho \\
Uruapan* & Uruapan & Pomacuaran & Paracho \\
Jicalan* & Uruapan & Quinceo & Paracho \\
Jucutacato* & Uruapan & Tanaco & Paracho \\
San Lorenzo* & Uruapan & San Felipe de los & Paracho \\
Sicuicho & Zacan & Urapicho & Paracho \\
Zacan & Zacan & & \\
\hline
\end{tabular}

Fuentes: Romero, Noticias para formar la historia y la estadística, pp. 36-39; "Noticia no. 16", en Memoria leída ante la legislatura, 1869, p. 123; "Noticas hidrográficas", en Memoria sobre los diversos ramos, 1886, pp. 39-43, 58-59 y 87-90.

* Comunidades donde se llevó a cabo reparto de tierras entre 1868 y 1875. $\because$ Comunidades en las que hay indicios de posible reparto de tierras entre 1868 y 1875 .

Por otro lado, estaba lo que por contraste denominaré la meseta baja, con mucho mayor acceso a cuerpos y corrientes de agua y, por tanto, donde era posible la agricultura de irrigación. Por lo regular, el cultivo de riego y el de temporal coexistían y se mezclaban. Como en la meseta alta, el maíz también era el cultivo más importante, seguido del trigo, pero la escala de la producción, en general, solía ser comparativamente mayor y las cosechas más frecuentes (dos al año). Al igual que en las tierras altas, se cultivaba gran variedad de frutas; sin embargo, a diferencia de las serranías elevadas, la siembra de cultivos como el añil, la caña de azúcar y (hasta principios de la década de 1890) el café se practicaba con relativa amplitud. Las conexiones comerciales en la meseta baja, además, eran más amplias y se extendían a 
mercados fuera de la región (la tierra caliente michoacana, el Bajío, la ciudad de Morelia, la parte este de Jalisco y, en menor medida, la Ciudad de México). ${ }^{18}$

El desigual acceso al agua también condicionó los patrones de asentamiento de haciendas y ranchos a lo largo del territorio de la meseta. En la meseta alta, donde el agua era escasa y por tanto no se podía practicar la agricultura de irrigación, la presencia de terratenientes y agricultores particulares era más bien limitada. De hecho, no existe registro de hacienda alguna y una buena parte de los ranchos, aunque muchas veces dados en arriendo a particulares, pertenecía a las mismas comunidades. La competencia por la tierra y otros recursos, en consecuencia, se daba en buena medida entre comunidades vecinas. La población, en general, también tendía a ser más uniforme y la diferenciación social interna menos pronunciada. Ello de ninguna manera hacía de las comunidades de la meseta alta paradigmas de igualdad y armonía. Como en cualquier comunidad, había rivalidades internas y familias e individuos más influyentes y acaudalados que otros (a veces, de hecho, sensiblemente más influyentes y acaudalados). Con todo, las comunidades

18 Véanse fuentes en cuadro 1. También "Catálogo de las frutas", pp. 34-35, 42, 45-46, 58-59, 61, 64-65, 71-72; y "Noticia no. 3 sobre ganadería"; SÁnchez DíAz, Breve historia del café. Las diferencias entre las comunidades de la meseta baja y la meseta alta no deben interpretarse como una división simple entre comunidades pobres y ricas. A diferencia de la mayoría de las comunidades de las tierras bajas, algunas comunidades de las tierras altas (como Chaparan, Comachuen o Corupo) poseían importantes rebaños de ovejas. Por su parte, las tierras de Cherán, como señala Embriz Osorio, "Propiedad, propietarios, pueblos indios", p. 237, muy probablemente rebasaban la significativa suma de 20000 hectáreas. 
indígenas y la propiedad comunal eran dominantes en esta parte de la región. ${ }^{19}$

\section{Cuadro 2}

NÚMERO DE RANCHOS Y HACIENDAS

EN LA MESETA PURÉPECHA

\begin{tabular}{ccc}
\hline Año & Ranchos & Haciendas \\
\hline 1822 & 81 & 28 \\
1873 & 81 & 16 \\
1880 & 170 & 20 \\
1886 & 98 & 25 \\
1909 & 319 & 22 \\
1910 & 193 & 21 \\
\hline
\end{tabular}

Fuentes: Martínez de Lejarza, Análisis estadístico; Rodríguez, Índice de los pueblos del estado de Michoacán; "División Territorial. Cuadro no. 9", en Memoria presentada a la legislatura del estado, 1882; Memoria presentada al Congreso de la Unión, 1887; Índice alfabético de la división territorial del estado de Michoacán, 1909, y AGN, FOP, A, "Inventario relativo a Estadística Agrícola. Michoacán, 1910”, leg. 2, c. 8, exp. 1.

En contraste, al permitir la irrigación, la presencia de abundantes ríos y otros cuerpos de agua en la meseta baja sirvió de imán para el establecimiento de haciendas y ranchos orientados a la agricultura comercial. ${ }^{20}$ Como resultado, las comunidades de la meseta baja enfrentaban mayor competencia por parte de terratenientes, rancheros y pequeños propietarios. El principal producto de la mayoría de las

19 Además de las fuentes citadas en el Cuadro 1 y la nota 18, véase "Noticia no. 5 de la propiedad urbana”.

${ }^{20}$ Sobre las haciendas y los hacendados michoacanos, véase CHOwnING, Wealth and Power y Sánchez Díaz, Los cultivos tropicales. 
haciendas y ranchos, sin embargo, era también el maíz, lo que de alguna manera limitaba (pero no impedía del todo) la apropiación de tierras comunales para la explotación de cultivos comercialmente más lucrativos. Mucho más interesados en hacerse de tierras que pertenecían a las comunidades estaban los numerosos arrendatarios y pequeños propietarios que poblaban esta parte de la meseta. En términos generales, la composición demográfica de las tierras bajas era comparativamente más diversa $y$, muy importante, las desigualdades dentro de las comunidades también eran, si no drásticas, más notorias. Aunque de ninguna manera avasalladas, en suma, las comunidades y sus propiedades comunales no eran dominantes en la meseta baja. ${ }^{21}$

\section{DOS LEYES EN CONFLICTO}

Este era, pues, el mundo (uno de ellos al menos) en el que los liberales pretendían intervenir y al que buscaban transformar desde muy temprano después de la independencia. La primera ley de reparto elaborada por el congreso de Michoacán fue publicada en 1827, acompañada al año siguiente de su reglamento. ${ }^{22}$ Sin embargo, la fragmentación

${ }^{21}$ Además de las fuentes citadas en el cuadro 1 y la nota 19, véase "Noticia no. 5 de la propiedad urbana"; AGHPEM, Distrito de Uruapan, Hijuela, t. 2, "Padrón de terrenos de la Sección $3^{a}$ del Sur en Tancítaro Año 1872", ff. 78b-179b; AGHPEM, Distrito de Uruapan, Hijuela, t. 14, "Padrón de terrenos de la Sección 4 ${ }^{\text {a }}$. del Poniente en Tancítaro Año 1872”, ff. 1-65b, y AGHPEM, Distrito de Uruapan, Hijuela, t. 2, "Padrón de terrenos de la Sección $1^{a}$ del Norte en Tancítaro Año 1872", ff. 14bis-77.

22 Para la ley de 1827, véase Coromina, Recopilación de leyes, vol. 2, pp. 61-62. Para el reglamento de 1828 véase Coromina, Recopilación de leyes, vol. 3, pp. 29-35. 
y disputas políticas que caracterizaron a las décadas posteriores a 1821 frenaron en buena medida la aplicación de la primera política de reparto esbozada en aquellas primeras leyes. ${ }^{23}$ En 1851, el Congreso de Michoacán retomó el proyecto y expidió una segunda ley de reparto. Poco después, como se sabe, el gobierno federal, encabezado entonces por Ignacio Comonfort, elaboró su propia ley, la primera de alcance nacional y dirigida también contra las propiedades de la Iglesia. ${ }^{24}$ Ambas leyes, la del Congreso michoacano y la del ministro Lerdo, no tuvieron ningún efecto inmediato significativo en la meseta purépecha. La guerra civil que les siguió y el conflicto contra el ejército de Napoleón III y sus aliados conservadores mexicanos obligaron a los liberales a replantear sus prioridades. ${ }^{25}$

Independientemente de su limitado impacto inmediato, sin embargo, había diferencias sutiles, pero de fondo, entre

${ }^{23}$ Hay, con todo, algunos indicios de repartos parciales en San Gabriel y en Los Reyes. Véase AGHPEM, SG, G, Hijuelas, Distrito de Uruapan, vol. 11, p. 155. Para una discusión de la transformación de las comunidades indígenas en Michoacán en la primera mitad del siglo XIX, véase Cortés Máximo, "La desamortización de la propiedad indígena”, pp. 263-301; Cortés Máximo, De repúblicas de indios, y García Ávila, Las comunidades indígenas.

${ }^{24}$ Para las discusiones de los legisladores en el Congreso de Michoacán previas a la promulgación de la ley de reparto de 1851 véase, AHCEM, $A P$, exp. 2, c. 14, Libro de Actas Públicas del Noveno Congreso no. 8. El contenido de la ley michoacana de reparto puede consultarse en CoromiNA, Recopilación de leyes, vol. 11, pp. 195-205. Para la ley federal, véase el conocido volumen de Labastida, Colección de leyes, pp. 4-5 y 9-13.

${ }^{25} \mathrm{Al}$ respecto véase el muy revelador intercambio entre el entonces gobernador de Michoacán, Gregorio Ceballos, y el ministro de Hacienda Miguel Lerdo de Tejada en Coromina, Recopilación de leyes, vol. 11, pp. 164-166. 
la ley estatal y la federal, diferencias por lo demás ignoradas tanto por la tradición clásica como por la literatura reciente, a pesar de que a la postre resultaron ser cruciales cuando los liberales regresaron al poder en 1867. Si bien ambas leyes compartían el objetivo general de acabar con la propiedad comunal y tenían como blanco específico las tierras de común repartimiento y las tierras adicionales de cultivo y pastoreo, en realidad proponían cosas muy distintas y lo hacían desde posiciones diferentes e incluso discordantes.

Por un lado, la ley michoacana de 1851 prohibía expresamente que personas ajenas a las comunidades reclamaran como suyas tierras comunales. Todavía más, ordenaba de manera inequívoca que la división y el reparto de terrenos se hicieran de manera lo más igualitaria posible, esto es, proponía (salvo en casos excepcionales) que las tierras comunales fueran repartidas en porciones idénticas en tamaño y número a cada uno de los miembros de las comunidades. Así, la ley michoacana no sólo excluía a arrendatarios y pequeños y grandes propietarios del reparto, sino que buscaba equilibrar (terminar, de hecho) las desigualdades materiales existentes dentro de las comunidades, compensando a los miembros más vulnerables a expensas de los más favorecidos y con más y mejores tierras. Al menos en potencia, la ley estatal de reparto promovía - basada en un igualitarismo radical, aunque problemático - una reforma profunda no sólo de la propiedad, sino de la vida social, económica e incluso política de las comunidades.

La Ley Lerdo, por otro lado, estaba muy lejos de pretender algo similar. Su foco, a diferencia de la ley michoacana, no eran los miembros de las comunidades indígenas. En el centro de la ley federal estaban los usufructuarios y arrendatarios 
de tierras en general, sin importar su procedencia o pertenencia comunitaria. Al menos en la meseta purépecha, esto abría la posibilidad de que personas ajenas a las comunidades, en particular quienes arrendaban algunas de las tierras comunales adicionales, se apropiaran de los terrenos que usufructuaban. La Ley Lerdo, por otro lado, tampoco decretaba nada parecido a un reparto de tierras igualitario. De hecho, en tanto que lo que realmente le importaba era convertir a los usufructuarios en propietarios, su aplicación no suponía alterar en lo más mínimo la distribución de la tierra (fuera desigual o no) tal cual existía ya dentro de las comunidades. En otras palabras, en contraste con la ley michoacana de reparto, no había en la Ley Lerdo ningún atisbo de impartir "justicia" o intención alguna de resarcir y compensar a los miembros más vulnerables de las comunidades. Comparada con la ley del estado de Michoacán, la Ley Lerdo no representaba ninguna amenaza sustancial al statu quo en una buena parte de las comunidades de la meseta purépecha -y más en especial, en la meseta baja, donde la diferenciación social dentro de las comunidades solía ser más notoria. ${ }^{26}$

Las diferencias entre ambas leyes, que en realidad lo eran entre dos formas distintas del liberalismo decimonónico, habrian de permanecer latentes por muchos años después de su expedición en la década de 1850 . No fue sino hasta

${ }^{26}$ Para una discusión más detallada de las diferencias entre la Ley Lerdo y la ley michoacana de reparto, véase Pérez Montesinos, "Poised to Break”, pp. 156-162 y 182-184. 
finales de la década de 1860 y la primera mitad de la de 1870 que surgirían en la práctica, forzadas no por los funcionarios y políticos liberales en Morelia y la Ciudad de México, sino por los arrendatarios, pequeños propietarios y comuneros de la meseta purépecha.

Sucesos de índole general, sin embargo, crearon el ambiente propicio para que esto fuera posible. El triunfo republicano sobre el segundo imperio renovó el ímpetu liberal por el reparto de tierras comunales en varias partes del país, incluido Michoacán. La victoria parecía haber otorgado a los liberales una excepcional posición de fuerza para retomar su política contra la propiedad comunal. La desamortización de bienes eclesiásticos, el otro gran eje de la reforma liberal de la tierra, había sido ya puesta en marcha. El poder de la Iglesia se encontraba sustancialmente socavado. Los conservadores - en teoría, aliados potenciales de las comunidades indígenas en la lucha contra la desamortización y el reparto - habían sido también derrotados y se encontraban desacreditados. No había, entonces, adversarios políticos por los que preocuparse. Si acaso, había sólo que lidiar con los rompimientos dentro del bando vencedor que, no obstante, no representaban una amenaza seria al consenso en torno de los principios y las políticas liberales. ${ }^{27}$ En suma, se había abierto un claro para volver sobre los ya viejos esfuerzos por desmantelar la propiedad comunal.

Sin embargo, al menos en Michoacán, el verdadero impulso por poner en marcha la política de reparto no vino tanto de la fortaleza de los liberales, sino de su patente

${ }^{27}$ Sobre el consenso liberal, véase el trabajo de Hale, The Transformation of Liberalism. 
debilidad. Años de conflictos armados, constantes cambios de gobierno y la sucesión una tras otra de administraciones erráticas habían lastimado seriamente las finanzas públicas del estado, al grado de estar virtualmente en bancarrota. Dos datos ilustran con claridad este punto: entre 1827 y 1867 Michoacán tuvo en promedio casi dos gobernadores por año; entre 1857 y 1861, durante la guerra de reforma, el gasto militar del estado consumió en promedio poco más de $72 \%$ de todos los recursos públicos del estado. ${ }^{28}$

Poner fin a la propiedad comunal, entonces, sólo podía convertirse en una prioridad para las autoridades michoacanas si al mismo tiempo contribuía a resarcir el ruinoso estado del erario. Fue así como la necesidad de recaudar recursos para el funcionamiento del gobierno llevó a las autoridades de Michoacán a instituir en 1868 un nuevo impuesto sobre todas las fincas rústicas y urbanas del estado. Los ingresos del nuevo impuesto, según explicaban las autoridades, ayudarían a cortar el lazo de dependencia que por décadas había atado al gobierno a los intereses de prestamistas abusivos. Sin embargo, había también un propósito paralelo. Se buscaba de manera explícita alentar la fragmentación de tierras comunales por medio de una serie de incentivos y presiones que volvieran más atractiva la propiedad particular que la comunal a ojos de los propios miembros de las comunidades. ${ }^{29}$

28 Véase Bravo Ugarte, Historia sucinta, apéndice 1, pp. 553-558, y LeRdo de TeJAdA, Tesorería general.

29 Véase Coromina, Recopilación de leyes, 1887, vol. 19, pp. 21-29. Como señala Menegus, Los indios en la historia, pp. 51-52, la relación entre impuestos, tierras y desamortización, aunque central, es a menudo soslayada. La motivación fiscal detrás del fraccionamiento de la propiedad comunal es parte del análisis integral de Kourí, A Pueblo Divided, 
La ley que regulaba el nuevo impuesto establecía claramente que aquellas comunidades que mantuvieran sus tierras sin dividir estarían, sin excepción, sujetas al pago de la nueva carga fiscal. Por el contrario, aquellas que dividieran sus tierras y las convirtieran en propiedades particulares estarían exentas de cualquier pago por un número determinado de años. Todavía más, todas las propiedades con un valor menor a 100 pesos dejarían de pagar el impuesto de forma permanente. Puesto que muchas de las propiedades en manos de los miembros de las comunidades, tomadas en lo individual, estaban por debajo de este valor, de ser fraccionadas no pagarían el nuevo gravamen. En contraste, tomadas en conjunto, como si se tratara de una sola gran propiedad, las tierras comunales podían llegar a pagar importantes sumas de dinero. ${ }^{30}$ De esta forma, los comuneros de la meseta (y seguramente también de otras partes de Michoacán) se vieron frente a la disyuntiva de seguir sin dividir sus tierras y lidiar después con el nuevo gravamen o bien dividirlas para gozar de exenciones e impuestos mucho más bajos.

Se trataba de una decisión en extremo difícil, sobre todo si consideramos que hasta entonces las comunidades nunca en su historia habían tenido que pagar impuestos por la posesión de sus tierras. La nueva política recaudatoria de las autoridades liberales de Michoacán representaba un hito respecto a la política colonial que en ningún momento supuso un gravamen directo sobre las propiedades comunales.

pp. 171-174. Para una discusión general centrada en la Ley Lerdo, véase Escobar, "La desamortización de tierras civiles corporativas".

30 Coromina, Recopilación de leyes, vol. 19, pp. 21-29. 
La situación era aún más comprometida para los miembros de las comunidades porque, en paralelo, el gobierno de Michoacán había revivido el intento de aplicar la ley estatal de reparto de tierras de 1851. Por sí sola, esta ley, como la anterior de 1827, poco podía lograr y no necesariamente representaba una amenaza inminente para las comunidades de la meseta purépecha. Ya antes habían sorteado varios intentos por aplicarla y no había razones para pensar que esta vez lo podrían volver hacer. Salvo que ahora las circunstancias eran distintas. Ahora la ley estatal de reparto se presentaba como una alternativa viable e incluso deseable para evitar (o al menos paliar) el pago del nuevo impuesto sobre la tierra. Además, cabía la posibilidad de que con su aplicación los miembros menos favorecidos de las comunidades, esto es, los que menos y peores tierras tenían, reclamaran terrenos que les ayudaran a enmendar su difícil situación.

Sin embargo, de llevarse a cabo conforme a la ley estatal de 1851, el reparto de tierras afectaría directamente a los miembros más favorecidos de las comunidades y, en menor medida, a los arrendatarios de tierras comunales. Para los comuneros favorecidos, la política de igual número y tamaño de tierras para todos no representaba ningún beneficio. Al contrario, los obligaba a ceder tierras que en la práctica consideraban suyas, aunque bajo el entendido de que formaban parte de la dotación general de la comunidad. Al mismo tiempo, puesto que sus tierras seguramente rebasarían el tope de 100 pesos para reclamar exención de impuestos, se verían eventualmente orillados a pagar el nuevo gravamen de forma individual. Si bien también tendrían que pagar alguna suma de no dividirse los terrenos comunales, la carga se distribuiría entre todos los miembros de la 
comunidad. Por su lado, los arrendatarios tampoco veían con buenos ojos la política de reparto. Su aplicación potencialmente eliminaba los arreglos que tenían con las comunidades y, más importante aún, los excluía del todo (a diferencia de la Ley Lerdo) de la posibilidad de apoderarse de las tierras que usufructuaban.

Enfrentados a la doble presión de la política de reparto y el nuevo gravamen sobre la tierra, y anticipando la pérdida de tierras y prerrogativas, algunos arrendatarios y comuneros decidieron actuar en consecuencia y apelar no a la ley de reparto estatal, sino a ley federal de desamortización. ${ }^{31}$ Sabían bien que con ello evitarían que se les aplicaran a ellos los aspectos que no gustaban de la ley estatal y que protegerían su posición frente a los efectos potencialmente igualadores del reparto. Sabían también que la ley federal, al privilegiar la calidad de arrendatario y usufructuario por sobre la pertenencia a la comunidad, les permitiría a unos mantener sus más y mejores tierras y a otros hacerse de los terrenos comunales que arrendaban. Para ellos, la Ley Lerdo no representaba una amenaza, como sí lo representaba la ley michoacana de reparto. En otras palabras, para ellos la Ley Lerdo significaba menos un desafío que una herramienta para salvaguardar sus intereses.

Su decisión, nunca anticipada por las autoridades de Michoacán, motivó una ola de debates y divisiones dentro de muchas de las comunidades de la meseta purépecha. ${ }^{32}$ Lo

${ }^{31}$ AGHPEM, SG, G, Hijuelas, Distrito de Uruapan, vol. 15, ff. 16, 21 y 26; AGHPEM, $S G, G$, Hijuelas, Distrito de Uruapan, vol. 23, f. 120; Coromina, Recopilación de leyes, vol. 19, pp. 61-62.

32 Véase AGHPEM, SG, G, Hijuelas, Distrito de Uruapan, vol. 23, ff. 180 182. También, Purnell, “'With All Due Respect'”, pp. 93-94 y 112-113. 
significativo, sin embargo, es que esos debates y divisiones siguieron un patrón muy definido que se ajustaba de manera precisa a la geografía física y social de la región. Salvo una excepción (la comunidad de Nahuatzen), una mayoría dentro de las comunidades de la meseta alta cerró filas y rechazó de tajo (con éxito, cabe señalar) tanto la aplicación de la ley estatal de reparto como la de la ley federal de desamortización. Esto es, ahí donde las diferencias sociales y materiales entre los miembros de las comunidades, aunque lejos de ser inexistentes, tendían a ser menores; donde la escasez de agua inhibió la creación de haciendas y la expansión de la agricultura comercial a gran escala; donde los ranchos no eran mayoría y donde la presencia de pequeños propietarios y arrendatarios era comparativamente limitada; ahí, en suma, donde la propiedad comunal era dominante, los intentos por fraccionarla (ya sea con base en la Ley Lerdo o en la ley michoacana de 1851) no prosperaron. Ello incluso a pesar de que dentro de las comunidades se sabía de antemano que eventualmente habrían de lidiar con el impuesto sobre la tierra indivisa y con nuevas presiones por parte de las autoridades michoacanas para que se llevara a cabo el reparto de tierras.

En contraste, las características de la meseta baja hicieron más propicias las divisiones dentro de las comunidades e incrementaron las posibilidades de llevar a cabo tanto el reparto estatal de tierras como los reclamos de tierras según los prescribía la Ley Lerdo. Si bien en su conjunto el peso de la propiedad comunal en las tierras bajas era importante, lo cierto es que su ascendencia (a diferencia de las tierras altas) estaba limitada por la presencia de haciendas y numerosos ranchos. Todavía más importante, puesto que el número de 
arrendatarios y pequeños propietarios era significativamente más nutrido en las tierras bajas, los incentivos y las oportunidades para reclamar (con éxito, también cabe señalar) tierras de comunidad fueron mucho mayores. La diferenciación social dentro de las comunidades, como se apuntó, era de igual modo mayor. No por casualidad fue de ahí, de la meseta baja, de donde provino el grueso de los primeros reclamos individuales de tierras por parte de algunos comuneros y arrendatarios. No es tampoco de sorprender que en términos generales los debates dentro de las comunidades de la meseta baja terminaran por girar no en torno de si resistir la división de las tierras comunales (rechazándola de tajo, como lo hizo la mayoría en la meseta alta), sino en torno de si llevarla a cabo según lo proponía la ley del estado de Michoacán o según lo proponía la ley federal de desamortización.

Al final lo que prevaleció fue una mezcla. Entre 1870 y 1875 , en poco más de la mitad (por lo menos) de las comunidades de la meseta baja (más Nahuatzen en la meseta alta) se adjudicaron en propiedad particular una parte sustancial de las tierras de común repartimiento, al menos una parte de las tierras en arrendamiento y, en ciertos casos, algunas fracciones de cerros (cosa que, en principio, no permitían ni la ley estatal ni la ley federal). En la ciudad de Uruapan, una mayoría dentro de los barrios de Santiago, San Pedro, La Magdalena, San Juan Bautista y San Miguel optó por hacerlo según la Ley Lerdo de 1856. En los barrios de San Francisco y San Juan Evangelista, por el contrario, se favoreció la ley michoacana de 1851; en San Juan Evangelista, de hecho, la adjudicación llegó a incluir uno de sus cerros. En Jucutacato, por su parte, predominó 
igualmente la ley michoacana. Así también ocurrió en las comunidades de Sevina y Jicalán. En Nahuatzen no sólo prevaleció una combinación de la política federal y estatal, sino que las adjudicaciones involucraron (como en San Juan Evangelista, pero de modo mucho más pronunciado) varios de sus cerros. Ambas políticas, la de reparto y la de desamortización, también se aplicaron en Apo y Tancítaro, con la diferencia de que ahí (sobre todo en Tancítaro) las adjudicaciones probablemente llevaron a la disolución de la propiedad comunal en su conjunto. ${ }^{33}$

En general, el fraccionamiento de las tierras comunales en la meseta baja y Nahuatzen tuvo resultados ambiguos. En conjunto, todo parece indicar que una mayoría de comuneros logró retener una parte significativa de sus terrenos. Con todo, también es cierto que muchas tierras antes consideradas como posesiones comunales pasaron en propiedad particular a manos de arrendatarios, pequeños y medianos propietarios y comuneros acomodados. Incluso en aquellas comunidades en las que la división de tierras se dio con arreglo a la ley estatal, nunca hubo nada cercano a una verdadera redistribución. Los miembros más necesitados de las comunidades no sólo no obtuvieron (salvo en casos limitados) tierras adicionales, sino que quedaron aún más expuestos a perder los terrenos que poseían. Las adjudicaciones se llevaron a cabo con desarreglo, sin apego a las especificaciones señaladas en la ley de 1851 y en medio de reclamos y disputas entre bandos rivales. En las comunidades en que se

${ }^{33}$ Para un tratamiento más detallado de lo sucedido entre 1870 y 1875 en estas comunidades, véase Pérez Montesinos, "Poised to Break", pp. 200-214. 
llegaron a aplicar tanto la política federal como la michoacana los desarreglos fueron aún mayores y la distribución de tierras tanto más sesgada y opaca. En última instancia, los más beneficiados con las políticas de reparto y desamortización (además de los arrendatarios y pequeños propietarios locales) tendieron a ser los grupos que anteriormente gozaban de una posición más holgada dentro de las comunidades, ya sea porque se hicieron de más y mejores terrenos durante el fraccionamiento de las tierras comunales o porque simplemente no se alteró en lo esencial la tradicional distribución de tierras. El reparto, en otras palabras, reforzó el statu quo cuando no contribuyó a aumentar las desigualdades existentes en las comunidades antes del reparto y la desamortización.

\section{CIENTOS DE PEDAZOS}

Y aun así, el impacto de las políticas liberales parece a la distancia limitado. Después de todo, hasta donde la evidencia disponible deja ver, la mayoría de los habitantes de las comunidades de la meseta lograron sortear la ola de repartos y adjudicaciones de los primeros años de la república restaurada. Todavía más, aunque el discurso de las autoridades estatales y federales seguiría siendo beligerante, en la práctica el ímpetu por acabar con la propiedad comunal disminuyó significativamente. Los enredos, las divisiones y las disputas que acompañaron al reparto, las habían convencido de desistirse de promover activamente el fraccionamiento sin concesiones de los terrenos en manos de las comunidades. Las secuelas de aquella ola, sin embargo, probaron 
ser duraderas y en muchos aspectos tan incisivas como la aplicación frontal de la política de reparto.

En efecto, a partir de mediados de la década de 1870 las tierras de las comunidades indígenas de la meseta experimentaron una sutil pero insidiosa fragmentación que se extendió hasta el comienzo (e incluso el transcurso) de la revolución mexicana. A lo largo de los años, como los archivos notariales y de la propiedad de Michoacán lo atestiguan, ${ }^{34}$ los miembros de las comunidades enajenaron cientos de parcelas, lotes, casas y terrenos de distinto valor y tamaño. Esto sucedió incluso en aquellas comunidades en las que en su momento se había rechazado con éxito lo establecido por las leyes de reparto y desamortización. El efecto acumulado de estas enajenaciones no puso en entredicho el régimen de propiedad comunal en la meseta. Con todo, fue lo suficientemente poderoso como para ocasionarle desde adentro numerosas grietas. ${ }^{35}$

Las razones detrás de estas enajenaciones son múltiples y complejas; dos cambios generales, sin embargo, ayudan a darles sentido. En primer lugar, el fin de la prohibición a la compraventa de tierras en manos de los comuneros. La ley estatal de 1851 había establecido una serie de candados para evitar la pérdida inmediata de propiedades una vez que se llevara a cabo el reparto de tierras entre los miembros de

\footnotetext{
${ }^{34}$ Desafortunadamente, los acervos históricos (al menos los correspondientes al siglo xIX y principios del xx) se encuentran en general en mal estado y sin catalogarse, tanto en el Archivo General de Notarías de Michoacán como en el Archivo del Registro Público de la Propiedad de Michoacán.

${ }^{35}$ Para un proceso similar y paralelo en otra región de México, véase Menegus, "La venta de parcelas", pp. 71-90.
} 
las comunidades. Entre otras cosas, los comuneros (o parcioneros, como las autoridades liberales les llamarían) sólo podían vender las tierras adjudicadas hasta cuatro años después del reparto. Esta restricción, sin embargo, fue revocada a finales de la década de 1860 para facilitar la división de tierras. La única prohibición que permaneció en pie fue la de enajenar tierras ejidales, montes y fundos legales, aunque la venta de propiedades individuales y familiares dentro del fundo legal estaba permitida. ${ }^{36}$ Antes de las políticas liberales, ciertamente, la transferencia a terceras personas de terrenos pertenecientes a la comunidad no era desconocida, pero su carácter ilícito establecía al menos ciertos límites a esta práctica. Suprimidos esos límites, los incentivos para llevarla a cabo se incrementaron sensiblemente.

El aumento de la población en la meseta, el segundo factor general de cambio, trajo consigo estímulos y presiones adicionales que también contribuyeron a la multiplicación de las enajenaciones. En efecto, de acuerdo con los datos disponibles, entre 1868 y 1910 la población total de la región pasó de 58777 a 93553 habitantes, un aumento importante de poco más de $60 \%$ en apenas cuatro décadas. Aunque es difícil ofrecer un dato preciso con base en las estadísticas de la época, es probable que los habitantes de las comunidades constituyeran cuando menos $45 \%$ de la población total. Los efectos del aumento demográfico entre las comunidades, sin embargo, no fueron uniformes. Quizá fueron mayores en la meseta baja, en donde se concentraba alrededor de $70 \%$ de la población total de la región. También

36 Véanse Coromina, Recopilación de leyes, vol. 11, pp. 199-200; y Coromina, Recopilación de leyes, vol. 19, p. 158. 
fueron más sustanciales entre las comunidades cuyas tierras de cultivo eran comparativamente más limitadas y, por tanto, tenían menos margen de acción para ajustarse a los cambios demográficos y dar sustento satisfactorio a una población en crecimiento. El aumento poblacional, en todo caso, pegó con mayor fuerza a los miembros de las comunidades que menos y peores tierras tenían. Para ellos, cualquier incremento (incluso un incremento moderado) amenazaba seriamente la precaria capacidad material que tenían para garantizar la subsistencia de sus familias, además de hacerlos sensiblemente más vulnerables a perder sus tierras. ${ }^{37}$

La enajenación de tierras tuvo lugar según dos patrones distintos. El primero de ellos consistía simplemente en actos de compraventa directos en los que las propiedades automáticamente pasaban de una mano a otra una vez realizado el pago por parte del comprador. El segundo patrón se daba de acuerdo con una figura (de origen medieval y luego trasplantada a América) conocida como pactos de retroventa. En principio, los pactos de retroventa no buscaban estrictamente la adquisición de una propiedad. Se trataba, en realidad, de una especie de crédito en la que los compradores extendían en calidad de préstamo una suma de dinero equivalente al valor de la propiedad. A cambio, los

${ }^{37}$ Para una discusión de cómo históricamente los aumentos poblaciones han afectado con mayor rigor a los grupos con menos tierras y recursos véase Goldstone, Revolution and Rebellion. Para los datos sobre la población en la meseta purépecha, véanse "Noticia no. 1", en Memoria leída ante la legislatura, 1869, pp. 65-68; "División Territorial. Cuadro número 9", en Memoria presentada a la legislatura del estado, 1882; Velasco, Geografía y estadística, p. 164; Censo y división territorial, pp. 16 y 90; y Tercer censo de población, vol. 1, pp. 204 y 206. 
"vendedores" se comprometían a pagar dicha suma en un periodo de tiempo acordado por ambas partes. Legalmente, la propiedad pasaba de modo temporal a manos de los compradores, quienes se comprometían a no venderla a terceras personas y regresarla a los dueños originales en cuanto se realizara el pago del préstamo. Sin embargo, de no realizarse el pago en el tiempo acordado, la propiedad pasaba permanentemente a la parte acreedora compradora. ${ }^{38}$

En tanto forma de crédito, los pactos de retroventa muchas veces ofrecían a los miembros de las comunidades un respiro temporal para enfrentar tiempos difíciles. Sin embargo, también dieron pie a numerosas pérdidas de tierras y propiedades. Después de todo, las retroventas eran en buena medida producto de la necesidad más que de la búsqueda de lucro. Aquellos que se apoyaban en ellas eran con frecuencia (aunque no exclusivamente) quienes más carencias tenían y, en consecuencia, quienes más apuros enfrentaban para saldar sus deudas. Todavía más, se trataba de individuos que, ahora más que nunca, veían cómo sus tierras sólo alcanzaban para amparar a algunos, pero ya no a todos los miembros de sus crecientes familias, en especial a los más

${ }^{38}$ Los pactos de retroventa no eran sólo propios de la meseta purépecha. Existían también en otras partes de Michoacán e incluso en otras partes del país. Sobre el origen de esta figura y su uso en México, y en particular en Veracruz, véase Léonard, "Mecánica social del cambio institucional. Privatización de la propiedad comunal y transformación de las relaciones sociales en Los Tuxtlas, Veracruz" (ensayo presentado en el XVI Congreso Internacional de la AHILA, San Fernando, Cádiz, 6 al 9 de septiembre de 2011). Para casos de retroventas en otras zonas de Michoacán véase Franco Mendoza, La ley y la costumbre. 
jóvenes, quienes eran los que más riesgo corrían de quedarse del todo sin tierras. ${ }^{39}$

Las élites local, regional y hasta estatal encontraron innegables beneficios en la compraventa y retroventa de las tierras de los miembros de las comunidades en la meseta. Terratenientes connotados como Feliciano Vidales, Manuel Campos y Espiridión Coria terminaron haciéndose de los terrenos de más de un parcionero por medio de los pactos de retroventa. Un grupo aún más nutrido y heterogéneo de notables locales adquirió por esa misma vía numerosas propiedades. A largo plazo, este grupo fue probablemente el que más favorecido se vio por las enajenaciones hormiga de las tierras en las comunidades. Se trataba de pequeños y medianos comerciantes y agricultores, de miembros acaudalados de las comunidades, de dueños de tiendas y otros negocios locales. Había entre ellos incluso abogados y profesionistas. Su posición de relativa holgura y sus fuertes ligas e intereses dentro de las comunidades les permitían asumir con cierta facilidad y naturalidad el papel de acreedores locales y también acumular propiedades por compras directas y otros medios informales. Así, por ejemplo, Sebastián

${ }^{39}$ Para algunos ejemplos de pactos de retroventa véase AGNM, $U$, col. de Copias de Escrituras, Libro de protocolo del notario Lic. Vicente de la Peña, 1879, no. 33. "Venta de un terreno con pacto de retroventa otorgado por Don Francisco y Don Benito Pahuamba a Doña Jacoba Álvarez", s. p.; AGNM, U, colección de Copias de Escrituras, Libro de protocolo del notario Lic. Eduardo Ruíz, 1880, no. 17. "Escritura de retroventa otorgada por Don Octaviano Ochoa en favor de Casimiro Pirita”, s. p.; AGNM, $U$, Colección de copias de escrituras públicas, Libro de protocolo del notario Lic. Pascual Arias, 1882, no. 78. Escritura de venta con pacto retroactivo, otorgada por el Ciudadano Manuel Aparicio en favor del Ciudadano Florentino Bravo", ff. 136-137. 
Turja en Cherán, de quien Carl Lumholtz dijo a mediados de la década de 1890 (quizá con un poco de exageración) que valía unos 100000 pesos. O miembros de prominentes familias purépechas como Luis Eiquihua en Parangaricutiro, quien todavía en 1920 poseía alrededor de 2500 ha de tierra, el equivalente a casi $12 \%$ de las 21000 ha de la comunidad. Personajes como doña Jacoba Álvarez, Florentino Bravo y Vicente Bravo, todos residentes de la ciudad de Uruapan, pero que prestaban dinero y poseían propiedades en Cherán, Cherán-Atzicurin, Paracho y San Felipe. ${ }^{40}$

No es posible afirmar que las enajenaciones en la meseta -facilitadas por las leyes liberales y alimentadas por el aumento de la población - derivaron de manera generalizada en una drástica concentración de tierras en pocas manos. Es muy probable que la mayoría dentro de las comunidades continuara en posesión de sus parcelas, lotes, solares y casas. No hay duda, sin embargo, de que con el paso del tiempo se consolidó una pequeña élite local que, al menos en parte, construyó su fortuna a expensas de los miembros menos favorecidos de las comunidades. Al mismo tiempo, una minoría numerosa de comuneros vio reducidos sus patrimonios y en muchos casos incluso hasta perdidos por completo. Para ellos las alternativas eran generalmente migrar a las ciudades en búsqueda de empleo o a lugares como la tierra caliente michoacana, en donde las haciendas cañeras y arroceras padecían de una crónica escasez de trabajadores.

\footnotetext{
${ }^{40}$ Véase Lumholtz, Unknown Mexico, vol. 2, p. 391; Garibay Orozco, Comunalismos, pp. 321 y 349, y, entre otros, AGNM, $U$, col. de Copias de Escrituras, Libro de protocolo del notario Lic. Vicente de la Peña, 1879, no. 33. "Venta de un terreno con pacto de retroventa otorgado por Don Francisco y Don Benito Pahuamba a Doña Jacoba Álvarez”, n. p.
} 
Con frecuencia, no obstante, terminaron trabajando como medieros en las tierras de las haciendas y ranchos locales y también, notablemente, en las tierras de miembros más acomodados dentro de las comunidades. ${ }^{41}$

\section{MILLONES DE DURMIENTES}

Las adjudicaciones de tierras de común repartimiento y otras pequeñas propiedades minaron el patrimonio de muchos miembros de las comunidades. Lo hicieron, no obstante, de un modo silencioso y sin provocar divisiones ni conflictos mayores. Pocos en el gobierno de Michoacán, por otro lado, veían con la misma determinación que antes el desmantelamiento de la propiedad comunal. Muchos años después del fin del primer reparto (1875), la cuestión parecía haber quedado, si no saldada, apaciguada. Sin embargo, hacia finales de la década de 1880 y a lo largo de la de 1890 , los debates y divisiones en torno del reparto de tierras comunales volverían a surgir con fuerza. Lo notable es que este resurgimiento vendría primero no como resultado del interés renovado de las autoridades liberales por retomar su propia política de reparto, sino desde dentro de las mismas comunidades. Fuerzas más allá de su entero control llevarían a algunos grupos dentro de las comunidades a tomar la iniciativa para enfrentar nuevos desafíos a la integridad, ya no de sus tierras de cultivo y propiedades familiares, sino de los abundantes bosques comunales - el tercer

41 Garibay Orozco, Comunalismos, pp. 334-336, 342-346 y 349, ofrece un agudo análisis del caso de Parangaricutiro. 
componente esencial del régimen comunal, hasta entonces sólo marginalmente vulnerado.

En efecto, entre 1890 y 1914 la industria maderera de Michoacán se erigiría como una de las más importantes del país, compartiendo los primeros lugares con estados como Chihuahua, Durango o Veracruz. Durante este breve pero intenso periodo, la explotación de madera adquirió una trascendencia tal para la economía de Michoacán que llegó a convertirse en la tercera actividad más lucrativa de todo el estado, sólo por debajo de la producción de maíz y trigo, pero por encima de la muy rentable (y más sonada) producción de arroz y caña de azúcar de la tierra caliente. ${ }^{42}$ Para 1901, Michoacán era ya (por mucho) el principal productor de madera de pino en México - el pino y el encino eran los árboles más comunes y abundantes en el estado y los que más ganancias reportaban a nivel nacional. Ese año, la producción michoacana llegó a concentrar arriba de 40\% del volumen de la producción de pino a nivel nacional, equivalente a poco más de $30 \%$ de su valor total en el país. Para 1907, el volumen de madera de pino michoacana había disminuido a un cuarto del total nacional (aunque era en términos absolutos mayor que en 1901), pero su valor había aumentado a un notable $40 \%$ del total. ${ }^{43}$

42 AGN, FOP, Agricultura, leg. 2, c. 8, exp.1, Michoacán, Inventario relativo a Estadística Agrícola, 1910. Para la importancia de los cultivos comerciales de la tierra caliente véanse Sánchez Díaz, Los cultivos tropicales y Pureco Ornelas, Empresarios lombardos.

${ }^{43}$ Véase el cuadro 3. El libro ya clásico de Vos, Oro verde, sigue siendo el análisis más completo y sugerente sobre la industria maderera del México decimonónico y de la primera mitad del siglo xx (el libro, de hecho, también abarca partes de Guatemala). Oro verde, sin embargo, gira alrededor de la explotación de maderas preciosas (en particular la caoba). La historia 
Cuadro 3

PRODUCCIÓN DE MADERA DE PINO EN MÉXICO

\begin{tabular}{llllll}
\hline & 1901 & & \multicolumn{3}{l}{1907} \\
\hline Estado & $\begin{array}{l}\text { Toneladas } \\
\text { métricas }\end{array}$ & $\begin{array}{l}\text { Valor } \\
\text { pesos) }\end{array}$ & Estado & $\begin{array}{l}\text { Toneladas } \\
\text { métricas }\end{array}$ & $\begin{array}{l}\text { Valor } \\
\text { (pesos) }\end{array}$ \\
\hline Michoacán & 104174 & 526886 & Michoacán & 174229 & 2669471 \\
Durango & 26771 & 445760 & Durango & 59804 & 902515 \\
Chihuahua & 60380 & 230468 & Chihuahua & 27605 & 781310 \\
Veracruz & 8916 & 182000 & Puebla & 86741 & 499767 \\
Nuevo León & 20962 & 110153 & Veracruz & 23402 & 387797 \\
Subtotal & 221203 & 1495267 & Subtotal & 371781 & 5240860 \\
Total (nacional) & 242604 & 1732082 & Total (nacional) & 715042 & 6690471 \\
\hline
\end{tabular}

Fuentes: Peñafiel, Anuario estadístico, 1902, pp. 529-537; Peñafiel, Anuario estadístico, 1912, pp. 566-580.

Los motores detrás de este rápido y sorprendente crecimiento fueron principalmente dos. Por un lado, el ya referido aumento de la población; no sólo en la meseta purépecha, sino en Michoacán y sus estados vecinos - la población de Michoacán pasó de 618000 habitantes en 1869 a casi el millón en $1910 .{ }^{44}$ El uso de leña y carbón vegetal en actividades cotidianas esenciales como la preparación de alimentos y el calentamiento de los hogares había significado una de las más importantes fuentes de demanda de madera desde siempre. En la medida en que la población se fue incrementando,

del auge maderero a nivel nacional está aún por escribirse. Para un muy reciente y útil panorama general (con acento en Michoacán y Chihuahua), véase Boyer, Political Landscapes, pp. 25-59.

${ }^{44}$ Véanse Memoria leída ante la legislatura, 1869, pp. 65-68; Memoria presentada al Congreso, 1908, pp. 160-161; y Estadísticas sociales del porfiriato, 1956, p. 41. 
esta demanda fue creciendo exponencialmente. Un patrón similar sucedió con el aumento de actividades como la herrería, la vidriería, la fabricación de ladrillos y, a una escala más industrial, la minería y el refinamiento de azúcar. La urbanización que acompañó al aumento poblacional también estimuló el incremento en el uso de maderas y resinas para la construcción de nuevas casas, edificios y múltiples enseres que los adornaban y amueblaban. El efecto acumulado de todas estas actividades, como ya había señalado desde principios de la década de 1870 el naturalista y conservacionista pionero Gabriel Hinojosa, era enorme. ${ }^{45}$

Por otro lado, estaba un factor nuevo que con el tiempo terminaría por convertirse en uno de los emblemas de la época: el tendido de las vías del ferrocarril - cuya expansión comenzó a acelerarse precisamente a partir de la década de 1880. Ya el propio Hinojosa lo había visto con claridad; de construirse el camino de fierro en la República, decía, "el consumo de madera tiene que aumentar considerablemente". ${ }^{46}$ En efecto, la construcción de vías férreas no sólo requería de enormes cantidades de fierro y acero, sino de extraordinarios volúmenes de madera usados principalmente para la fabricación de durmientes - las vigas trasversales que fijan al suelo y unen entre sí a los rieles (y evitan así que los trenes, por su peso, se descarrilen).

Se ha estimado que por cada kilómetro de camino construido en el mundo en el siglo XIX se necesitaron alrededor

\footnotetext{
45 Véase Hinojosa, Memoria sobre la utilidad. También Boyer, Political Landscapes, p. 35. Para la importancia de los efectos del consumo cotidiano de madera antes de la era de los combustibles fósiles, véase Williams, Deforesting, pp. 160-166.

${ }^{46}$ Hinojosa, Memoria sobre la utilidad, p. 26.
} 
de 1640 durmientes en promedio. En 1840 había a nivel global alrededor de $11000 \mathrm{~km}$ de vías de ferrocarril, lo que equivalía a 18000000 de durmientes. A grandes rasgos, 494 durmientes requerían una hectárea de bosque para su fabricación, esto es, la construcción de 11000 km de camino podía consumir arriba de 36000 ha de bosque. Y esta cifra no toma en cuenta los millones más por cuenta de piezas reemplazadas. Como describe con elocuencia el historiador Michael Williams, después de 1865 "no hubo año en el que al menos 500000 ha de bosque [en el mundo] no fueran destruidas para hacer durmientes". En 1900, cuando se alcanzó un punto máximo, se usaron casi 860000000 de durmientes (entre nuevos y reemplazos), equivalentes a 3400000 ha de bosque -10000 veces Central Park o 5250 veces el Bosque de Chapultepec. ${ }^{47}$

Para 1911, el tendido de las vías del ferrocarril en México sumaba alrededor de $27000 \mathrm{~km}$, incluyendo vías secundarias y locales. ${ }^{48} \mathrm{El}$ sistema ferroviario en su conjunto, por tanto, debió necesitar poco más de 44000000 de durmientes. En otras palabras, y puesto que la mayoría de la madera (a diferencia del fierro y el acero, que eran importados) provenía de fuentes locales, por sí sola la construcción del ferrocarril fue probablemente responsable de la deforestación de

47 Véase Williams, Deforesting, pp. 242-245 (en especial, tablas 9.4 y 9.5). La cita corresponde a las pp. 244-245 (la traducción es mía). Dependiendo de las condiciones locales, la vida útil de los durmientes podía extenderse hasta siete años sin tratamientos químicos, cosa que no fue práctica común en la mayoría de los países del mundo sino hasta las primeras décadas del siglo xx.

${ }^{48}$ Para la extensión del sistema ferroviario, véase Haber, "Assessing the Obstacles”, pp. 1-32, y Ortiz Hernán, Los ferrocarriles de México, vol. 1. 
casi 90000 ha de bosque en el territorio mexicano. ${ }^{49}$ Esto sin contar la madera utilizada para reposiciones, así como para la construcción de puentes, estaciones y los postes para el cableado del telégrafo que acompañaron al tendido de las vías férreas. Es cierto que la deforestación no era necesariamente permanente. La regeneración de muchos bosques, dependiendo de las circunstancias, podía darse con el tiempo. Sin embargo, no hay duda de que el ferrocarril fue un elemento medular para el surgimiento del auge maderero, en el que Michoacán ocupó un lugar prominente.

No hay forma de saber, con la evidencia disponible, la proporción exacta con la que los bosques comunales de la meseta purépecha contribuyeron a dicho auge. No obstante, en vista de la notable magnitud de sus recursos forestales, es claro que esta fue significativa. El primer inventario de bosques levantado por el estado de Michoacán a mediados de la década de 1880 estimaba que el total de los bosques de la meseta ascendía a unas 350000 ha, de las cuales alrededor de 44\% (unas 152000 ha) le era atribuido en posesión a las comunidades indígenas de la región. Esta estimación, sin embargo, fue producto de apreciaciones generales hechas por autoridades locales y no producto de mediciones sistemáticas en el terreno. Una cifra aproximada más plausible para el total de bosques de la meseta en el último cuarto del siglo xIX puede situarse en alrededor de 250000 ha. De aceptarse el porcentaje atribuido a los bosques comunales por las autoridades de Michoacán, las comunidades

${ }_{49}$ Cifra que palidece si se la contrasta con las casi 251000 ha de bosque removidas para ese mismo año por la red de ferrocarriles de Estados Unidos (por mucho, la más grande del mundo). Véase Williams, Deforesting, p. 300 (la tabla 10.5, en particular). 
estarían en manos de unas 110000 ha de terrenos forestales (equivalentes a $47 \%$ de todas sus tierras). ${ }^{50} \mathrm{Tal}$ abundancia no tardaría en atraer la ambición y consiguiente oposición de propios y extraños en la meseta.

\section{EL SEGUNDO REPARTO, 1885-1914}

El auge maderero transformó de forma drástica el uso y el valor que se le daba a los bosques dentro de las comunidades. Como se anotó, los bosques ocupaban un lugar central en la economía de las familias y las comunidades. Sin ellos, la conducción de actividades cotidianas esenciales se hacía simplemente imposible. Además, si bien las actividades agrícolas proporcionaban el grueso del sustento de la mayoría, los bosques servían para suplementar (a veces de manera importante) los ingresos de un nutrido número de habitantes de las comunidades. Los bosques, en otras palabras, proveían materiales indispensables para construir trojes, elaborar tortillas, cocinar alimentos, calentar los hogares, elaborar carbón para su venta en mercados locales y regionales, tallar artesanías y, en una escala mayor, fabricar tejamaniles, vigas y tablas de todo tipo que luego se comerciaban en la región y más allá. Se trataba de una explotación que combinaba usos domésticos con actividades comerciales en pequeña y mediana escala. Su huella no era de ningún modo insignificante; a largo plazo, los quehaceres rutinarios en las comunidades ejercían una presión considerable sobre los bosques. Con todo, no se trataba de un uso intensivo y, muy importante, éste estaba restringido a los miembros de

50 Véase "Catastro de los bosques", pp. 95-110 y nota al pie número11. 
las comunidades. En efecto, a diferencia de las tierras adicionales de cultivo y pastoreo, los bosques rara vez se arrendaban; su importancia como generadores de ingresos comunitarios era más bien escasa (si no es que inexistente). ${ }^{51}$

En la medida en que la demanda de madera y otros productos forestales comenzó a crecer, el uso de los bosques comunales se fue modificando gradualmente. Hacia finales de la década de 1880 y durante toda la de 1890, la aparición de cuadrillas de hombres con hachas y cubetas para recolectar resina de los árboles en terrenos comunales se hizo cada vez más frecuente. Poco a poco, también, fueron floreciendo en el bosque campamentos eventuales dispuestos para cortar, dentro de perímetros acotados, la mayor cantidad de árboles en el menor tiempo posible. La madera cortada era luego procesada en aserraderos modestos, pero que cada vez con mayor frecuencia eran mecanizados. Acabado el corte intensivo de un perímetro determinado, los campamentos se levantaban en búsqueda de nuevas áreas que explotar (dejando detrás pequeños pero cuantiosos claros en el bosque)..$^{52}$

De este modo, numerosas secciones de bosques comunales a lo largo y ancho de la meseta empezaron a ser arrendadas a un grupo creciente de pequeños y medianos madereros dueños de aserraderos. Con frecuencia, sin embargo, los arrendamientos eran llevados a cabo por individuos o grupos de individuos a título personal o, a veces, a nombre de las comunidades, pero sin consentimiento formal de la mayoría (como reclamaban apoderados, representantes de

\footnotetext{
${ }^{51}$ Véase nota 16.

52 Véase Boyer, Political Landscapes, p. 36.
} 
comunidad y hasta autoridades municipales). En otras ocasiones, el acceso y utilización de los bosques comunales se daba de modo enteramente informal, sin que mediara de por medio acuerdo o contrato alguno. En otras más, se llegaba incluso a la apropiación y la venta directas por parte tanto de algunos miembros de las comunidades como de personas de fuera (o por ambos en colusión). En efecto, las enajenaciones de tierras que habían seguido al fin del primer reparto comenzaron a ampliarse en los años del auge maderero más allá de los terrenos familiares y de común repartimiento. Ahora también, incluso cuando muchas transacciones eran dudosas o de plano ilegales, el bosque se fragmentaba. ${ }^{53}$

Pronto, los arrendamientos y apropiaciones de terrenos forestales comenzaron a dividir a los miembros de las comunidades entre quienes promovían los arriendos y cesiones parciales de bosque para fines particulares, y quienes se oponían a ellos o buscaban mayor control de la explotación forestal y orientar las ganancias hacia los fondos comunales. Todavía más, las disputas entre comunidades vecinas por límites territoriales empezaron a repuntar en la década de 1890. Estas disputas suelen caracterizarse como una parte lógica y hasta "natural" de las relaciones entre comunidades. Ciertamente, algunas de ellas tenían orígenes añejos y también acostumbraban reavivarse periódicamente. No obstante, nunca se daban de manera arbitraria ni espontánea. Respondían en cada ocasión a razones muy concretas y distintas. Lo que distinguió a las disputas limítrofes de la década de1890 fue el lugar central que tuvieron los bosques

53 Pérez Montesinos, “Poised to Break”, pp. 255-268. 
en ellas. En efecto, muchos de los linderos en conflicto estaban ocupados por cerros y tierras forestales. Ahora que los bosques habían adquirido un valor y uso comercial extraordinarios y que, en consecuencia, eran más vulnerables a los intereses y ambiciones de propios y extraños, se hacía más urgente que nunca la necesidad de definir su propiedad. En el contexto del auge maderero, los viejos conflictos territoriales se volvieron, en realidad, conflictos por el bosque.

Motivadas por el deseo de ganarles la partida a sus vecinos rivales, y asegurar con ello la propiedad de los bosques en disputa, algunas autoridades y cabecillas comunales (incluso en varias comunidades en las que años atrás hubo oposición mayoritaria a la aplicación de las leyes liberales) hicieron lo impensable: solicitar expresamente a las autoridades de Michoacán el reparto general de sus tierras -incluyendo, por supuesto, sus terrenos forestales.$-{ }^{54}$ De hecho, estas solicitudes tenían también el propósito de poner un freno a los arriendos y enajenaciones de porciones de bosques comunales dentro de las comunidades y por parte de empresarios madereros. Se trataba, sin duda, de un movimiento audaz que de cristalizarse podía liquidar (o al menos aplacar) de un solo golpe los problemas causados por el auge maderero. Las peticiones de reparto, sin embargo, no dieron los resultados esperados. Las autoridades michoacanas vieron con buenos ojos el reparto de tierras comunales, pero no concedieron la adjudicación de terrenos forestales en disputa. La propiedad de estos terrenos tendría que dirimirse

54 Véanse, por ejemplo, las solicitudes de San Gabriel y Paracho, AGHPEM, SG, G, Hijuelas, Distrito de Uruapan, vol. 11, ff. 159-160 y AGHPEM, SG, G, Hijuelas, Distrito de Uruapan, vol. 12, f. 35. 
después, una vez llevado a cabo el reparto. No es de extrañarse que las comunidades solicitantes decidieran dar marcha atrás a sus peticiones. Para entonces, sin embargo, ya habían reavivado el interés del gobierno michoacano por la cuestión del reparto - sin haber logrado, tampoco, detener el avance de las apropiaciones de terrenos forestales. ${ }^{55}$

Así, al comienzo del nuevo siglo, la situación de los bosques comunales en la meseta purépecha ( $y$, sin duda, en otras regiones boscosas de Michoacán) era ya significativamente compleja. En poco más de diez años, los terrenos forestales se habían vuelto objeto de múltiples enajenaciones y arrendamientos y eran reclamados por igual por cuadrillas de resineros, dueños de pequeños y medianos aserraderos, grupos de comuneros rivales y pueblos vecinos. La etapa más intensiva de la explotación maderera, sin embargo, estaba apenas por comenzar. Una serie de compañías madereras, manejadas por un grupo compacto de empresarios y administradores británicos y estadounidenses, cambiaría en los próximos años (hasta el golpe huertista contra Madero) la escala y el ritmo del negocio de la madera en la meseta. ${ }^{56}$

Estas nuevas compañías no desplazaron del todo a los pequeños y medianos madereros que hasta entonces habían dominado la explotación de los bosques. Sin embargo, rápidamente se hicieron del control de la parte más sustancial del negocio. Producto de sus mejores conexiones y acceso a los circuitos financieros de Uruapan, Morelia y la Ciudad de México, estaban mejor capitalizadas que sus

55 Pérez Montesinos, “Poised to Break”, pp. 255-268.

56 Uno de los primeros en identificar la importancia de estas compañías fue Guzmán Ávila, Michoacán y la inversión, pp. 109-119 y 123 y 133. 
competidoras locales. Ello les permitió primero adquirir los negocios de sus rivales más importantes y luego aumentar el equipo y la capacidad de sus aserraderos hasta construir un verdadero complejo industrial de cientos de hectáreas (el aserradero La Maestranza) ubicado en un sitio conocido como Conuy. También incitaron el proceso de reconversión de los arrendamientos de terrenos forestales. La Compañía Nacional de Maderas (surgida en 1901, la primera de las nuevas grandes compañías) adquirió los contratos de arriendo que sus predecesoras más pequeñas habían celebrado no hacía mucho con algunas comunidades locales. A diferencia de los arrendamientos parciales de la década de 1890, sin embargo, estos contratos ya no sólo involucraban algunas fracciones de terrenos forestales, sino los bosques de las comunidades firmantes en su totalidad. Los plazos del arriendo, de igual modo, se hicieron más amplios, hasta alcanzar en algunos casos los 30 años, con opción a ser prolongados por otros $20 . .^{57}$

Las autoridades michoacanas, por su parte, habían permanecido en buena medida a la zaga de los cambios suscitados por el auge de la madera. Las peticiones de reparto de las comunidades, aunque bienvenidas, las habían tomado por sorpresa y poco habían hecho para prevenir la escalada de tensiones provocadas por las enajenaciones $\mathrm{y}$ arriendos de terrenos forestales en la meseta. La reciente creación de compañías madereras cada vez más grandes sólo confirmaba la magnitud de los cambios. Fue así que en el verano de 1902 se expidió, acompañada de su respectivo

57 Pérez Montesinos, “Poised to Break”, pp. 269-280. 
reglamento, una nueva y última ley estatal de reparto. ${ }^{58}$ Esta ley suele ser interpretada como la consecuencia lógica de décadas de esfuerzos por acabar con la propiedad comunal en el estado, en particular, porque ordenaba el reparto de todas las tierras comunales, incluyendo los ejidos y montes de las comunidades (los montes, por cierto, también habían sido incluidos en la primera ley de reparto de 1827). La ley de 1902, sin embargo, era en buena medida el resultado coyuntural de poco más de una década de fricciones y disputas en torno del control y explotación de los bosques comunales en la meseta y, sin duda, en otras zonas del estado. Era, en otras palabras, hija del auge de la madera.

La trascendencia de la ley, en todo caso, al menos para la meseta purépecha, no consistió en que dio origen a una nueva ola de repartos. En realidad, sólo llegó a sancionar adjudicaciones parciales de algunas secciones de bosque que habían estado en disputa antes de su expedición. Su importancia, por el contrario, radicó en que ampliaba sensiblemente el grado de intervención del gobierno de Michoacán en los asuntos internos de las comunidades, incluyendo la designación de representantes y el manejo de los bosques. Por un lado, la ley determinó que cualquier transacción de tierras comunales, incluidos los bosques, debía primero contar con la autorización del gobierno o de lo contrario sería declarada nula. Por el otro, otorgó al poder ejecutivo la facultad de autorizar la designación de representantes de comunidad; en otras palabras, si bien los miembros de las comunidades podían proponer sus propios representantes, éstos debían ser aprobados y reconocidos expresamente

58 Coromina, Recopilación de leyes, 1903, vol. 36, pp. 510-512 y 516-532. 
(por escrito) por los funcionarios de la Oficina de Gobierno en Morelia.

Con estas disposiciones, el gobierno de Michoacán buscaba poner fin a la doble problemática de las enajenaciones de terrenos forestales comunales y las divisiones que habían causado dentro de las comunidades - en tanto se aplicaba la política de reparto. La ley de 1902, de hecho, terminó por avivar aún más las disputas. Las acusaciones de transferencias ilícitas de extensiones de bosques comunales se multiplicaron, muchas veces siguiendo las líneas divisorias marcadas por grupos rivales de comuneros y sus aliados locales. La oficialización de la figura de los representantes de comunidad, de igual modo, no sirvió para detener las pugnas internas. Por el contrario, ahora las partes en disputa comenzaron a competir por el reconocimiento institucional de las autoridades michoacanas. El puesto había adquirido una importancia estratégica que bien podía significar la diferencia entre tener al gobierno como aliado o tenerlo como adversario. La designación de representantes de comunidad no era entonces sólo el producto de un golpe de mano por parte de las autoridades, sino también el resultado de intensas y complejas pugnas políticas locales. No es de extrañarse que los nuevos representantes solieran durar muy poco en sus puestos y fueran removidos con sorprendente frecuencia, acusados por igual de no oponerse con suficiente firmeza a la explotación de los bosques y de no permitirla para beneficio colectivo de la comunidad. ${ }^{59}$

En cualquier caso, las desavenencias que rodeaban a la figura de los representantes de comunidad se hicieron

59 Pérez Montesinos, "Poised to Break”, pp. 269-280. 
todavía más agudas con la propagación de los contratos entre comunidades y compañías madereras. Para 1913, cuando se firmó el último contrato, la Compañía Industrial Michoacana (la última de las grandes empresas madereras que seguía hasta esa fecha operando en la meseta) acumulaba acuerdos de arrendamiento con alrededor de la mitad de las comunidades de la meseta. Como ya se dijo, los contratos de arrendamiento daban a las compañías acceso libre a los bosques comunales por amplios periodos de tiempo. Esto ha llevado a que sean calificados como claramente dolosos para las comunidades. Los términos de arrendamiento, sin embargo, también ofrecían algunos incentivos concretos que en un momento dado podían resultar atractivos para las comunidades (o, al menos, para ciertos grupos dentro de las comunidades). A cambio del libre acceso a los bosques, las compañías tenían que pagar cada año una cantidad nada despreciable que podía llegar hasta casi 7000 pesos y que como mínimo era de 1000 . Además, los miembros de las comunidades podían seguir haciendo uso de los bosques para llevar a cabo sus actividades domésticas y productivas. Finalmente, en la medida en que las compañías estaban principalmente interesadas en el corte y extracción de madera, más que en la propiedad de los terrenos, los contratos no cuestionaban la propiedad comunal. ${ }^{60}$

La importancia de los contratos de arrendamiento, de este modo, no residió principalmente en su carácter fraudulento y pernicioso. Tal interpretación parece sugerir, contrario a lo que señala la evidencia, que los miembros de las

60 Para los contratos véanse AGHPEM, SG, G, Hijuelas, Distrito de Uruapan, vol. 20, ff. 1-119, y ARPPM, $R G D U$, 1. 2, t. 4, ff. 56-72. 
comunidades desconocían por completo el contenido de los contratos. Ignora, además, el contexto de movilización (en favor y en contra de la explotación del bosque) que había precedido a estos convenios. La resonancia de los contratos de arrendamiento estribó, entonces, en que transformaron (más allá de la tenencia de la tierra) el uso que durante décadas (siglos, en realidad) se le había dado a los bosques comunales de la región. En efecto, en los años del auge de la madera, y por primera vez en su larga historia, los terrenos forestales pasaron de ser primordial y exclusivamente utilizados en pequeña y mediana escala a ser utilizados de forma intensiva e industrial; pasaron de orientarse principalmente a cubrir las necesidades y respaldar las labores productivas de los miembros de las comunidades, a servir a las necesidades y demandas de una economía mucho más grande (y, por tanto, mucho más voraz) de la que los empresarios madereros y sus clientes eran sólo un eslabón. Los bosques comunales, cuyo uso, además, alguna vez estuvo limitado a los habitantes de las comunidades, eran ahora territorio abierto por el que podían deambulaban lo mismo propios que extraños.

Con todo, pese a su proliferación, no todos los contratos se llevaron a efecto. De hecho, es probable que la explotación más intensiva se haya concentrado sobre todo en algunas zonas al este de la meseta, en municipios como Tingambato y Nahuatzen. Aunque no sin costos, a veces altos (encarcelamientos, atentados, homicidios, incendios), en algunas comunidades los grupos que no aceptaron la legalidad y legitimidad de los arrendamientos lograron prevalecer. En otras ocasiones, los antagonismos giraron no tanto en torno de la oposición a los contratos y las compañías, 
sino en torno de la búsqueda de control por parte de grupos rivales de los ingresos generados por la renta de los bosques comunales. En algunas más, la firma de los convenios se dio tardíamente y no alcanzaron a trasladarse más allá del papel antes del fin del auge y el colapso de la producción maderera en 1914.

Para esa fecha, en realidad, la relación entre la Compañía Industrial Michoacana y muchas de las comunidades con las que había firmado contratos de arrendamiento estaba ya bastante descompuesta. ${ }^{61}$ La revolución mexicana no hizo sino acelerar esa descomposición. De hecho, hizo también algo aún más importante. Si bien al principio no puso en riesgo la continuidad de la producción de madera, en su momento, cuando el conflicto armado entró en su fase más aguda, terminó por destruir los dos pilares sobre los cuales se había alzado el negocio maderero entero. Por un lado, detuvo la expansión de la construcción de la red ferroviaria y, por tanto, acabó con la demanda de durmientes que había sido tan importante para instigar la explotación intensiva y a gran escala de los bosques. Por otro lado, llevó a la caída del sistema financiero del que tan ampliamente dependían compañías madereras como la Compañía Industrial Michoacana para salir a flote, ya no digamos para seguir expandiendo sus operaciones. Sin crédito ni demanda, la explotación forestal industrial se derrumbó. ${ }^{62}$

61 Guzmán Ávila, Michoacán y la inversión, pp. 133-135, y Boyer, Political Landscapes, pp. 38-39. Martínez Aguilar, "El aserradero de Zatzio", pp. 195-221.

62 Para la continuidad y caída de distintas actividades económicas durante la Revolución, incluyendo el sistema financiero, véase HABER, RAzo y Maurer, The Politics of Property Rights. 
La industria maderera habría de resurgir después de la revolución, poco a poco y sin que alguna nueva gran compañía se hiciera del control de la explotación. En 1931, Lázaro Cárdenas, entonces gobernador de Michoacán, promulgó un decretó que volvió nulos los contratos que los representantes de las comunidades de la meseta firmaron con las compañías madereras entre 1902 y $1913 .{ }^{63}$ El decreto sancionaba lo que en los hechos, a ras de suelo, se había comenzado a fraguar. Pequeños y medianos madereros y resineros retomarían su ascendencia e influencia. También los miembros de las comunidades. Las divisiones y disputas internas, sin embargo, no cejarían. Los bosques de la meseta, para usar una reciente y hábil expresión de Christopher Boyer, se habían convertido en paisajes políticos, arenas de disputa y negociación entre intereses privados, colectivos y gubernamentales. ${ }^{64}$ Nuevos factores y condicionantes, a la vez muy distintos y parecidos a los que habían dado lugar a poco más de 40 años de reparto liberal, moldearían la historia de ese otro reparto que la revolución mexicana habría de originar.

\section{CONCLUSIÓN}

El momento por el que actualmente atraviesa la historiografía sobre la desamortización civil en México es por demás

${ }^{63}$ Véase Guzmán Ávila, Michoacán y la inversión, p. 135, y Boyer, Political Landscapes, p. 88.

${ }^{64}$ Boyer, Political Landscapes, pp. 10-14. El estupendo libro de Boyer, sin embargo, ubica el origen de estos paisajes políticos en el siglo xx, con la revolución mexicana. Como he tratado de mostrar aquí, el bosque se volvió un asunto altamente litigioso desde décadas antes, durante el porfiriato. Véase Espín Díaz, Tierra fría. 
estimulante. Cada año se publican nuevos trabajos sobre localidades que durante mucho tiempo los profesionales de la historia pasaron de largo, en parte por la aparente falta de materiales con los que trabajar y en parte porque, en el fondo, no se pensaba que su estudio pudiera cambiar de manera sustancial nuestro entendimiento general del proceso desamortizador. Aún quedan grandes superficies oscuras por iluminar, pero en el mapa de la desamortización hay hoy un creciente número de puntos resplandecientes que poco a poco han ido delineando veredas y avenidas por las cuales andar y continuar la exploración.

Con todo, el reconocimiento de nuevos terrenos - la expansión constante y general en las últimas décadas del estudio de la desamortización civil- se ha dado en buena medida de forma intuitiva y asistemática. Esta manera de proceder no es necesariamente algo que hay que reprochar. De hecho, ha estimulado el surgimiento continuo de nuevas investigaciones y con ello ha ayudado a reavivar y alterar un campo que durante largo tiempo experimentó pocos cambios y cuestionamientos. Sin embargo, también ha derivado en un cierto tipo de aproximación que por momentos privilegia de sobremanera el hallazgo empírico por sobre el análisis, el episodio por sobre la ilación de hechos, la sincronía por sobre la diacronía.

De ahí que la mayoría de los estudios especializados sólo ofrezca una serie de pistas desperdigadas aquí y allá, pero no criterios sistemáticos y generales de los cuales valerse para construir historias locales y regionales más integrales del proceso desamortizador. Sin estos criterios, desafortunadamente, será muy difícil la elaboración (cada vez más imperiosa) de trabajos comparativos y la realización (en un 
futuro próximo) de escritos de síntesis que vuelvan a dar al tema la visión de conjunto que perdió con el desdoro de buena parte del viejo canon. La naturaleza con frecuencia fragmentada y episódica de numerosos estudios recientes, en ese sentido, ha llevado a dejar de lado un hecho de fundamental importancia que muchos de los historiadores de la vieja guardia (y también algunos de la nueva, cabe señalar) habían notado con suma claridad. Esto es, que la transformación de la propiedad comunal tuvo lugar sólo cuando otras trasformaciones más generales de la sociedad en su conjunto ocurrieron primero.

Este trabajo, a diferencia de buena parte de la bibliografía actual, pone mucho mayor énfasis en el examen puntual de esas transformaciones. Los cambios más importantes se dieron en las leyes, la política en general, la política fiscal, el ritmo de crecimiento de la población y la economía. No se trata, en efecto, de esferas ajenas al conocimiento convencional de la historia profesional. Lo importante, sin embargo, es hacer notar que sólo en muy raras ocasiones se les ha examinado de modo sistemático en relación con el proceso desamortizador. Lo que aquí se plantea, además, es que esas transformaciones pueden considerarse comunes a casi todos los casos en los que la desamortización civil y otras políticas análogas dejaron su huella y que, por tanto, pueden servir a otros investigadores para estudiar diferentes regiones y localidades - siempre y cuando también se haga un análisis detallado de las muy particulares condiciones geográficas y materiales de los lugares que se inspeccionen.

El análisis específico del reparto liberal en la meseta purépecha aquí desarrollado, en ese sentido, no sólo busca ofrecer una visión integral (hasta ahora faltante) de esta región 
cardinal de Michoacán. También intenta arrojar luz sobre aspectos que pueden resultar relevantes para el estudio de la desamortización civil en su conjunto. Uno de esos aspectos está relacionado con la forma en que se ha abordado el marco legal de la desamortización. Aunque a últimas fechas se le ha otorgado a las leyes y reglamentos estatales una importancia que en la historiografía clásica sólo tuvo la Ley Lerdo y otras disposiciones federales, lo cierto es que aún se ha estudiado muy poco cómo es que ambos marcos legales, el federal y el estatal, interactuaron entre sí. A juzgar por lo sucedido en la meseta purépecha, la interacción entre ambos marcos no siempre fue armónica y mucho menos accesoria. Como este trabajo trató de explicar, la ley michoacana de 1851 y la Ley Lerdo de 1856 diferían en un aspecto nodal, a saber, que reparto y desamortización no suponían la misma cosa, ni en principio ni en la práctica. La existencia de este tipo de discrepancias suele pasar desapercibida para los especialistas de hoy. No así para los actores locales de la época, quienes estaban muy conscientes de ellas, acaso porque de eso dependía si mantendrían o no la posesión de sus tierras y, por tanto, buena parte de su sustento.

Otro aspecto poco estudiado del proceso desamortizador, iluminado por el análisis aquí presentado de la meseta purépecha, es la relación íntima que hubo entre políticas fiscales y políticas de la tierra. El carácter inédito del establecimiento de impuestos sobre la tierra por parte de los gobiernos liberales en la segunda mitad del siglo xix ha sido señalado en otras partes. El papel instrumental que dichos impuestos tuvieron en instigar el fraccionamiento de la propiedad comunal, sin embargo, sólo raramente ha sido foco de un escrutinio detallado. Las cargas impuestas por el 
gobierno de Michoacán sobre la propiedad no fueron, como podría pensarse, el resultado de un despliegue de fuerza por parte de las autoridades liberales. Por el contrario, como aquí se buscó argumentar, fueron el resultado de la necesidad de recaudar recursos para subsanar el maltrecho estado de las finanzas públicas. Fue esta necesidad la que terminó por hacer de la política recaudatoria un catalizador y complemento de la política de reparto. En otras palabras, el estado ruinoso de la administración pública fue un motor, no un impedimento, para la aplicación de la política de reparto en la meseta purépecha y en Michoacán en general. Queda por estudiarse si algo similar pudo también suceder en otras regiones y estados del país.

Un fenómeno al que igualmente podría otorgársele mayor consideración, presente en la meseta purépecha y que sin duda se replicó a lo largo y ancho de la República, es el de lo que rudimentariamente podemos denominar el fraccionamiento hormiga de la propiedad comunal. Si bien dicho fenómeno ha llamado la atención de algunos especialistas, hace falta ampliar aún más nuestro conocimiento acerca de quiénes en particular, por qué razones, cuándo y según qué medios enajenaron tierras de comunidad. El estudio de la meseta purépecha sugiere, por lo pronto, que parte de la respuesta a estas preguntas pasa por el análisis de los efectos (diferenciados) del aumento poblacional que caracterizó al siglo xIX mexicano. También sugiere que los sectores más sensibles a los cambios demográficos dentro de las comunidades fueron precisamente los más propensos a perder sus tierras, y que buena parte de las enajenaciones de terrenos fueron, en realidad, un subproducto y no el resultado inmediato y directo de las políticas liberales de la tierra. 
Advierte, además, que debemos dedicar mucho mayor tiempo y espacio al estudio en particular de los pactos de retroventa, medio cardinal por el cual se realizaron numerosas enajenaciones, pero del que hasta ahora sabemos poco.

Este trabajo, finalmente, trae a luz un suceso escasamente notado, ya no sólo por la historiografía de la desamortización civil, sino por la historiografía general del porfiriato y la revolución mexicana. El auge maderero experimentado a partir del último tercio del siglo XIX no ha despertado el interés que, por ejemplo, ha merecido el despunte de sectores como el minero, el financiero o el de cultivos comerciales de exportación como el henequén. Esta falta de interés es todavía más sorprendente cuando se considera el vínculo estrecho que hubo entre la industria maderera y la expansión del sistema ferroviario, suceso este último con frecuencia tomado como uno de los más representativos de la modernización porfiriana. Los ángulos desde donde puede abordarse el estudio de la explotación industrial de los bosques y su relación con el ferrocarril son muchos y atañen por igual, entre otras, a la historia económica, la ambiental, la laboral y la historia social. Este artículo, por lo pronto, espera haber mostrado la trascendencia general del fenómeno maderero; su peso fue especialmente importante para la meseta purépecha y Michoacán, pero sin duda también lo fue para otras regiones del país. De qué formas estuvo ligado a procesos de reparto y desamortización en esas otras regiones es algo que aún está por saberse. Este estudio quizá pueda servir para encontrar parte de las respuestas. 


\section{SIGLAS Y REFERENCIAS}

AGN, FOP, A Archivo General de la Nación, fondo Fomento y Obras Públicas, Agricultura, Ciudad de México.

AGNM, $U$ Archivo General de Notarías de Michoacán, fondo Uruapan, Ciudad de México.

AGHPEM, SG, G Archivo General e Histórico del Poder Ejecutivo de Michoacán, fondo Secretaría de Gobierno, Gobernación, Morelia.

AHCEM, AP Archivo Histórico del Congreso del Estado de Michoacán, fondo Actas Públicas, Morelia.

ARPPM, $R G D U$ Archivo del Registro Público de la Propiedad de Michoacán, fondo Registro de gravámenes en el Distrito de Uruapan, Morelia.

Acosta Espino, Gabriela y Arnulfo Embriz Osorio

“Territorios indios en la región Purhépecha, 1915-1940”, en GARDUÑo y otros, 1998, vol. 1, pp. 119-195.

Ávila García, Patricia

Escasez de agua en una región indígena. El caso de la Meseta Purépecha, México, El Colegio de Michoacán, 1996.

Azevedo Salomao, Eugenia María (ed.)

La vivienda purépecha. Historia, habitabilidad, tecnología y confort de la vivienda purépecha, Morelia, Universidad Michoacana de San Nicolás de Hidalgo, 2008.

BeALs, Ralph L.

Cherán: A Sierra Tarascan Village, Washington D. C., United States Government Printing Office, 1946.

Birrichaga, Diana y Carmen Salinas Sandoval

"Conflicto y aceptación ante el liberalismo. Los pueblos del Estado de México, 1856-1876", en Escobar Ohmstede (coord.), 2007, pp. 207-252. 
Boenm, Brigitte

"Las comunidades de indígenas de Ixtlán y Pajacuaran", en Escobar y Rojas (eds.), 2001, pp. 145-175.

BOyer, Christopher

Political Landscapes: Forests, Conservation, and Community in Mexico, Durham, Duke University Press, 2015.

Bravo Ugarte, José

Historia sucinta de Michoacán, Morelia, Morevallado Editores, 2007.

Buve, Raymond

"Un paisaje lunar habitado por bribones y sus víctimas. Mirada retrospectiva al debate sobre las haciendas y los pueblos durante el porfiriato (1876-1911)", en FALCón y Buve (comps.), 1998, pp. 121-151.

Calder, Ian, Thomas Hofer, Sibylle Vermont y Patrizio Warren

“Towards a New Understanding of Forests and Water", en Unasylva, 58:229 (2007), pp. 3-10.

Camacho Pichardo, Gloria

"Desamortización y reforma agraria en Ocoyoacac y Lerma", en Escobar Ohmstede, Sánchez Rodríguez y Gutiérrez Rivas (eds.), 2008, pp. 287-310.

Carrasco, Pedro (coord.)

La sociedad indígena en el centro y occidente de México, México, El Colegio de México, 1986.

"Catálogo de las frutas"

"Catálogo de las frutas, raíces, tubérculos que se producen y expenden en el estado de Michoacán de Ocampo", en Memoria sobre la administración pública, 1892, pp. 17-18, 38 y 42. 
"Catastro de los bosques"

"Catastro de los bosques y montes del Estado, que se formó en cumplimiento de lo dispuesto en la fracción II del artículo $2^{\circ}$ de la ley número 50 de 18 de Diciembre de 1882", en $\mathrm{Me}$ moria sobre los diversos ramos, 1885, pp. 95-110.

Censo y división

Censo y división territorial del estado de Michoacán verificado en 1900, México, Imprenta y Fotografía de la Secretaría de Fomento, 1905.

Chowning, Margaret

Wealth and Power in Provincial Mexico: Michoacan from the Late Colony to the Revolution, Stanford, Stanford University Press, 1999.

Congost, Rosa

"Property Rights and Historical Analysis: What Rights? What History?", en Past E Present, 181 (2003), pp. 73-106.

Coromina, Amador

Recopilación de leyes, decretos, reglamentos y circulares expedidas en el estado de Michoacán, Morelia, Imprenta de los hijos de Ignacio Arango, 1886, vols. 2, 3 y 11.

Recopilación de leyes, decretos, reglamentos y circulares expedidas en el estado de Michoacán, Morelia, Imprenta de los hijos de Ignacio Arango, 1887, vol. 19.

Recopilación de leyes, decretos, reglamentos y circulares expedidas en el estado de Michoacán, Morelia, Talleres de la Escuela Industrial Militar Porfirio Díaz, 1903, vol. 36.

Cortés Máximo, Juan Carlos

De repúblicas de indios a ayuntamientos constitucionales: pueblos sujetos y cabeceras de Michoacán, 1740-1831, Morelia, Universidad Michoacana de San Nicolás de Hidalgo, 2012.

"La desamortización de la propiedad indígena en una provincia mexicana. Los fines y efectos de la ley de 1827 sobre re- 
parto de tierras comunales en Michoacán”, en Relaciones, 134 (2013), pp. 263-301.

Embriz Osorio, Arnulfo

"Propiedad, propietarios, pueblos indios y reforma agraria en la región purhépecha, 1915-1940”, en Escobar OHMSTEde y Rojas Rabiela (coords.), 2001, pp. 233-271.

Escobar Ohmstede, Antonio

"Estudio introductorio. Haciendas, pueblos y recursos naturales en San Luis Potosí”, en Escobar Ohmstede y Gutiérrez Rivas (coords.), 2009, pp. 19-98.

Las estructuras agrarias. Pueblos de indios y propiedades privadas, México, Nostra Ediciones, 2010.

"La desamortización de tierras civiles corporativas en México: ¿una ley agraria, fiscal o ambas? Una aproximación a las tendencias en la historiografía”, en Mundo Agrario, 13:25 (2012), www.mundoagrario.unlp.edu.ar/. Consultado el 15 de mayo de 2016.

Escobar Ohmstede, Antonio (coord.)

Los pueblos indios en los tiempos de Juárez, México, Universidad Autónoma "Benito Juárez" de Oaxaca, Universidad Autónoma Metropolitana, 2007.

Escobar Ohmstede, Antonio y Mathew Butler

"Introduction: Transition and Closures in Nineteenth - and Twentieth- Century Mexican Agrarian History", en Escobar Ohmstede y Butler (eds.), 2013, pp. 33-76.

Escobar Ohmstede, Antonio y Mathew Butler (eds.)

Mexico in Transition: New Perspectives on Mexican Agrarian History, Nineteenth and Twentieth Centuries/ México $y$ sus transiciones: reconsideraciones sobre la historia agraria mexicana, siglos XIX y XX, México, Centro de Investigaciones y Estudios Superiores en Antropología Social, Llilas Benson, 2013. 
Escobar Ohmstede, Antonio y Jaqueline Gordillo

“Defensa o despojo? Territorialidad indígena en las Huastecas, 1856-1930”, en Escobar Оhmstede y otros, 1998, pp. $17-74$.

Escobar Ohmstede, Antonio y Ana María Gutiérrez Rivas (coords.)

Entretejiendo el mundo rural en el "oriente" de San Luis Potosí, México, Centro de Investigaciones y Estudios Superiores en Antropología Social, El Colegio de San Luis, 2009.

Escobar Ohmstede, Antonio y Teresa Rojas Rabiela (eds.)

Estructuras y formas agrarias en México, del pasado y del presente, México, Registro Agrario Nacional, Centro de Investigaciones y Estudios Superiores en Antropología Social, 2001.

Escobar Ohmstede, Antonio, Martín Sánchez Rodríguez y Ana María Gutiérrez Rivas (eds.)

Agua y tierra en México en el siglo XIX y XX, México, El Colegio de Michoacán, El Colegio de San Luis, 2008, vol. 1.

Escobar Ohmstede, Antonio y Frank Schryer

"Las sociedades agrarias en el norte de Hidalgo, 1856-1900", en Mexican Studies/Estudios Mexicanos, xviı:1 (1992), pp. $1-21$.

Escobar Ohmstede, Antonio y otros

Estudios campesinos en el Archivo General Agrario, México, Registro Agrario Nacional, Centro de Investigaciones y Estudios Superiores en Antropología Social, 1998.

Espín Díaz, Jaime L.

Tierra fría, tierra de conflictos en Michoacán, Zamora, El Colegio de Michoacán, Gobierno del Estado de Michoacán, 1986. 
Estadísticas sociales

Estadísticas sociales del porfiriato, 1877-1910, México, Talleres Gráficos de la Nación, 1956.

FALCón, Romana

México descalzo. Estrategias de sobrevivencia frente a la modernidad liberal, México, Plaza y Janés, 2002.

FALcón, Romana (ed.)

Culturas de pobreza y resistencia. Estudios de marginados, proscritos y descontentos. México, 1806-1910, México, El Colegio de México, Universidad Autónoma de Querétaro, 2005.

Falcón, Romana y Raymond Buve (comps.)

Don Porfirio presidente... nunca omnipotente. Hallazgos, reflexiones y debates, 1876-1911, México, Universidad Iberoamericana, 1998.

Franco Mendoza, Moisés

La ley y la costumbre en la Cañada de los Once Pueblos, $\mathrm{Za}-$ mora, El Colegio de Michoacán, 1997.

García Ávila, Sergio

Las comunidades indígenas en Michoacán. Un largo camino hacia la privatización de la tierra, Morelia, Universidad Michoacana de San Nicolás de Hidalgo, 2009.

García Mora, Carlos

El troje purépecha. Asiento, granero y oratorio del grupo doméstico, México, Tsimarhu Estudio de Etnólogos, 2012.

Garduño, María Rosa y otros

Estudios campesinos en el Archivo General Agrario, México, Registro Nacional Agrario, Centro de Investigaciones y Estudios Superiores en Antropología Social, 1998, vol. 1. 
Garibay Orozco, Claudio

Comunalismos y liberalismos campesinos. Identidad comunitaria, empresa social forestal y poder corporado en el México contemporáneo, Zamora, El Colegio de Michoacán, 2008.

Garibay Orozco, Claudio y Gerardo Bocco Verdinelli

Cambios de uso del suelo en la meseta purépecha (1976-2005), México, Secretaría de Medio Ambiente y Recursos Naturales, Instituto Nacional Electoral, Universidad Nacional Autónoma de México, 2011.

Goldstone, Jack A.

Revolution and Rebellion in the Early Modern World, Berkeley, University of California Press, 1991.

Gómez Santana, Laura y Maricela Gómez Santana

“Mujeres y propiedad social en Jalisco, 1876-1924”, en EscoBAR Y BUTLER (eds.), 2013, pp. 545-563.

Granados, Luis Fernando

En el espejo haitiano. Los indios del Bajío y el colapso del orden colonial en América Latina, México, Era, 2016.

Guerra, François-Xavier

México: del Antiguo Régimen a la Revolución, México, Fondo de Cultura Económica, 1991, t. II.

Guzmán Ávila, José Napoleón

Michoacán y la inversión extranjera, 1880-1911, Morelia, Universidad Michoacana de San Nicolás de Hidalgo, 1982.

Haber, Stephen

"Assessing the Obstacles to Industrialisation: The Mexican Economy, 1830-1940", en Journal of Latin American Studies, 24:1 (1992), pp. 1-32. 
Haber, Stephen, Armando Razo y Noel Maurer

The Politics of Property Rights: Political Instability, Credible Commitments, and Economic Growth in Mexico, 1876-1929, Cambridge, Cambridge University Press, 2003.

Hale, Charles

The Transformation of Liberalism in Late Nineteenth-Century Mexico, Princeton, Princeton University Press, 1990.

Hinojosa, Gabriel

Memoria sobre la utilidad de los bosques y perjuicios causados por su destrucción, Morelia, Imprenta de la Viuda é hijos de O. Ortiz, 1873.

Índice alfabético

Índice alfabético de la división territorial del estado de Michoacán de Ocampo, en orden de municipalidades, tenencias, haciendas y ranchos comprendidos en la ley de 20 de julio de 1909, Morelia, Escuela Industrial Militar, 1909.

Knowlton, Robert J.

"La individualización de la propiedad corporativa civil en el siglo xix: Notas sobre Jalisco", en Historia Mexicana, xxvin::1 (109) (jul.-sep. 1978), pp. 24-61.

"La división de las tierras de los pueblos durante el siglo xix: el caso de Michoacán", en Historia Mexicana, xL:1 (157) (jul.sep. 1990), pp. 3-25.

Kourí, Emilio

"Interpreting the Expropriation of Indian Pueblo Lands in Porfirian Mexico: The Unexamined Legacies of Andrés Molina Enríquez", en The Hispanic American Historical Review, 82:1 (2002), pp. 69-117.

A Pueblo Divided: Business, Property, and Community in Papantla, Mexico, Stanford, Stanford University Press, 2004. 
LABASTIDA, Luis G.

Colección de leyes, decretos, reglamentos, circulares, órdenes, $y$ acuerdos relativos a la desamortización de los bienes de corporaciones civiles y religiosas y a la nacionalización de los que administraron estas últimas, México, Tipografía de la Oficina Impresora de Estampillas, 1893.

Lerdo de Tejada, Francisco

Tesorería general y gefatura de hacienda del estado de Michoacán de Ocampo. Su cuenta é informe por los ingresos y egresos habidos en ambas oficinas, desde 19 de marzo de 1858 hasta 6 de febrero de 1862 en la primera, y 31 de enero del mismo año en la $2 d a$, Morelia, Imprenta de Ignacio Arango, 1864.

Lumholtz, Carl

Unknown Mexico: A Record of Five Years' Exploration among the Tribes of the Western Sierra Madre; in the Tierra Caliente of Tepic and Jalisco; and among the Tarascos of Michoacan, Nueva York, Charles Scribner's Sons, 1902, vol. 2.

Mallon, Florencia

Peasant and Nation: The Making of Postcolonial Mexico and Peru, Berkeley, University of California Press, 1995.

Marino, Daniela

"La desamortización de las tierras de los pueblos (centro de México, siglo XIx). Balance historiográfico y fuentes para su estudio", en América Latina en la historia económica. Boletín de Fuentes, 16 (2001), pp. 33-43.

"La modernidad a juicio: pleitos por la tierra y la identidad comunal en el Estado de México (municipalidad de Huixquilucan), 1856-1900”, en FALcón (ed.), 2005, pp. 237-264.

Martínez Aguilar, José Manuel

"El aserradero de Zatzio, un caso de la explotación de los bosques de Michoacán”, en Relaciones, 32: 127 (2011), pp. 195-221. 
Martínez de Lejarza, Juan José

Análisis estadístico de la provincia de Michoacán en 1822, Morelia, Filmax Publicistas, 1974.

McBRIDE, George M.

The Land Systems of Mexico, Nueva York, American Geographical Society, 1923.

Memoria leída

Memoria leída ante la legislatura de Michoacán en la sesión del día 30 de Julio de 1869 por el secretario de gobierno del estado, Lic. Francisco W. González, Morelia, Imprenta de O. Ortiz, 1869.

Memoria presentada

Memoria presentada al Congreso de la Unión por el secretario de estado y del despacho de Fomento, Colonización, Industria y Comercio de la República mexicana, México, Imprenta y Fototipia de la Secretaría de Fomento, 1908.

Memoria presentada

Memoria presentada al Congreso de la Unión por el secretario de estado y del despacho de Fomento, Colonización, Industria y Comercio de la República mexicana General Carlos Pacheco, correspondiente a los años trascurridos de enero de 1883 a junio de 1885, México, Oficina Tipográfica de la Secretaría de Fomento 1887.

Memoria presentada

Memoria presentada a la legislatura del estado de Michoacán de Ocampo, por el secretario de gobierno C. Lic. Néstor López, en la sesión del día 31 de Mayo de 1882, Morelia, Imprenta del Gobierno en Palacio, 1882.

Memoria sobre

Memoria sobre la administración pública del estado de Michoacán de Ocampo, leida ante la diputación permanente del 
congreso del mismo por el secretario del despacho Lic. Francisco Pérez Gil en la sesión del 13 de septiembre de 1892, Morelia, Talleres de la Escuela de Artes, 1892.

Memoria sobre los diversos ramos de la administración pública, leída ante el congreso del estado de Michoacán de Ocampo, en las sesiones del 21 y 23 de mayo de1885, por el secretario de despacho, Lic. Francisco Pérez Gil, Morelia, 1885, Morelia, Imprenta del Gobierno a cargo de José R. Bravo, 1885.

Memoria sobre los diversos ramos de la administración pública, leída ante el congreso del estado de Michoacán, en la sesión del día 25 de mayo de 1886, por el secretario del despacho Lic. Francisco Pérez Gil, Morelia, Imprenta del Gobierno, 1886.

Memoria sobre los diversos ramos de la administración pública, leida por el secretario del despacho, Lic. Francisco Pérez Gil, ante la diputación permanente del estado de Michoacán de Ocampo, en las sesiones de los dias 12, 13, y 14 de septiembre de1889, México, Litografía de la Escuela de Artes, 1889.

Mendoza García, J. Edgar

Municipios, cofradias y tierras comunales. Los pueblos chocholtecos de Oaxaca en el siglo XIX, Oaxaca, Universidad Autónoma "Benito Juárez" de Oaxaca, Universidad Nacional Autónoma de México, Universidad Autónoma Metropolitana-Azcapotzalco, Centro de Investigaciones y Estudios Superiores en Antropología Social, 2011.

Menegus, Margarita

"Ocoyoacac: una comunidad agraria en el siglo xIx", en Historia Mexicana, xxx:1 (117) (jul.-sep. 1980), pp. 33-78.

"La venta de parcelas de común repartimiento: Toluca, 18721900”, en Menegus y Cerutti (eds.), 2001, pp. 71-90.

Los indios en la historia de México, México, Fondo de Cultura Económica, Centro de Investigación y Docencia Económicas, 2006. 
La Mixteca Baja entre la revolución y la reforma. Cacicazgo, territorialidad y gobierno, siglos XVIII Y XIX, Oaxaca; Universidad Autónoma "Benito Juárez" de Oaxaca, Universidad Nacional Autónoma de México, 2012.

Menegus, Margarita y Mario Cerutti (eds.)

La desamortización civil en México y España (1750-1920), México, Universidad Autónoma de Nuevo León, Senado de la República, 2001.

Meyer, Jean

"Haciendas, ranchos, peones y campesinos en el porfiriato. Algunas falacias estadísticas", en Historia Mexicana, xxxv: 3 (139) (ene.-mar. 1986), pp. 477-509.

"La Ley Lerdo y la desamortización de las comunidades en Jalisco", en Carrasco (coord.), 1986, pp. 189-212.

"Noticia no. 1"

“Noticia no. 1", en Memoria leída ante la legislatura, 1869.

"Noticia no. 3"

"Noticia no. 3 sobre ganadería de las fincas rusticas del Estado", en Memoria sobre los diversos ramos, 1889.

"Noticia no. 5"

"Noticia no. 5 de la propiedad urbana del Estado [Distrito de Uruapan]", en Memoria sobre los diversos ramos, 1889.

"Noticias hidrográficas"

"Noticias hidrográficas", en Memoria sobre los diversos ramos, 1886, pp. 39-43, 58-59 y 87-90.

Ortiz Hernán, Sergio

Los ferrocarriles de México. Una visión social y económica. La luz de la locomotora, México, Ferrocarriles Nacionales de México, 1987, vol. 1. 
PANi, Erika (coord.)

Nación, Constitución y Reforma, 1821-1908, México, Centro de Investigación y Docencia Económicas, Fondo de Cultura Económica, Consejo Nacional para la Cultura y las Artes, Instituto Nacional de Estudios Históricos de las Revoluciones de México, Fundación Cultural de la Ciudad de México, 2010.

Peñafiel, Antonio

Anuario estadístico de la República Mexicana 1901, Oficina Tipográfica de la Secretaría de Fomento, 1902.

Anuario estadístico de la República Mexicana 1907, México, Oficina Tipográfica de la Secretaría de Fomento, 1912.

Pérez Hernández, José María

Compendio de la geografía del estado de Michoacán de Ocampo, México, Imprenta del Comercio de Nabor Chávez, 1872.

Pérez Montesinos, Fernando

"Poised to Break: Liberalism, Land Reform, and Communities in the Purépecha Highlands of Michoacán, Mexico, 1800-1915", tesis de doctorado en historia, Washington, D.C., Georgetown University, 2014.

Pureco Ornelas, Alfredo

Empresarios lombardos en Michoacán. La familia Cusi entre el porfiriato y la posrevolución, 1884-1938, Zamora, El Colegio de Michoacán, Instituto de Investigaciones Dr. José María Luis Mora, 2010.

Purnell, Jennie

"With All Due Respect: Popular Resistance to the Privatization of Communal Lands in Nineteenth-Century Michoacan", en Latin American Research Review, 34:1 (1999), pp. 85-121. 
Rodríguez, Anselmo

Índice de los pueblos del estado de Michoacán de Ocampo, con explicación del distrito político y rentístico á que pertenecen, el número de sus habitantes y las etimologias de varios de sus nombres, Morelia, Imprenta de O. Ortiz, 1873.

Romero, José Guadalupe

Noticias para formar la historia y la estadística del obispado de Michoacán presentadas a la Sociedad Mexicana de Geografía y Estadística en 1860, México, Vicente García Torres, 1862.

ROSEBERRY, William

“'El Estricto Apego a la Ley’. Ley liberal y derecho comunal en el Pátzcuaro porfiriano”, en Seneff (ed.), 2004, pp. 43-84.

SÁnchez Díaz, Gerardo

Breve historia del café en Michoacán, Morelia, Universidad Michoacana de San Nicolás de Hidalgo, Centro de Investigación y Desarrollo de Michoacán, Fundación Produce, 2006.

Los cultivos tropicales en Michoacán. Época colonial y siglo XIX, Morelia, Universidad Michoacana de San Nicolás de Hidalgo, Centro de Investigación y Desarrollo de Michoacán, Morevallado Editores, 2008.

SÁnchez Silva, Carlos (coord.)

La desamortización civil en Oaxaca, Oaxaca, Universidad Autónoma "Benito Juárez" de Oaxaca, Universidad Autónoma Metropolitana, 2007.

SCHENK, Frank

"Muchas palabras, poca historia: una historiografía de la desamortización de tierras comunales en México (1856-1911)", en Cuadernos de Historia Latinoamericana, 7 (1999), pp. 215-227.

Seneff, Andrew Roth (ed.)

Recursos contenciosos: ruralidad y reformas liberales en México, Zamora, El Colegio de Michoacán, 2004. 
STAuffer, Brian A.

"Community, Identity, and the Limits of Liberal State Formation in Michoacán’s Coastal Sierra: Coalcomán, 1869-1940”, en Escobar Ohmstede y Butler, 2013, pp. 149-180.

\section{Tercer censo}

Tercer censo de población de los Estados Unidos Mexicanos verificado el 27 de octubre de 1910, México, Oficina Impresora de la Secretaría de Hacienda, 1918, vol. 1.

Thomson, Guy P. C.

“¿Convivencia o conflicto? Guerra, etnia y nación en el México del siglo XIX”, en PANI (coord.), 2010, pp. 205-237.

Velasco, Alfonso Luis

Geografía y estadística del estado de Michoacán, Morelia, Universidad Michoacana de San Nicolás de Hidalgo, Centro de Investigaciones y Desarrollo del Estado de Michoacán [1895] 2005.

Vos, Jan de

Oro verde. La conquista de la Selva Lacandona por los madereros tabasqueños, 1822-1949, México, Fondo de Cultura Económica, 1988.

West, Robert C.

Geografía cultural de la moderna área tarasca, Zamora, El Colegio de Michoacán, Fideicomiso "Felipe Teixidor y Monserrat Alfau de Teixidor”, 2013.

Williams, Michael

Deforesting the Earth: From Prebistory to Global Crisis (an Abridgment), Chicago, University of Chicago Press, 2006. 
